\title{
Direct Evidence Of Sex In Symbiodiniaceae And A Hypothesis About Meiosis
}

\section{R.I. Figueroa ( $\nabla$ rosa.figueroa@ieo.es )}

Spanish Institute of Oceanography in Vigo. Subida a Radio Faro

\section{Howe-Kerr}

Rice University

\section{A.M.S. Correa}

Rice University

\section{Research Article}

Keywords: Symbiodiniaceae, climate change-driven ocean warming, meiosis

Posted Date: April 5th, 2021

DOI: https://doi.org/10.21203/rs.3.rs-347043/v1

License: (1) This work is licensed under a Creative Commons Attribution 4.0 International License. Read Full License 


\section{DIRECT EVIDENCE OF SEX IN SYMBIODINIACEAE AND A HYPOTHESIS ABOUT MEIOSIS}

Figueroa, R.I. ${ }^{{ }^{*}}$, Howe-Kerr, L.I. ${ }^{2}$, Correa, A.M.S. ${ }^{2 *}$

${ }^{1}$ Spanish Institute of Oceanography in Vigo. Subida a Radio Faro, 50. 36390 VIGO (SPAIN), email: rosa.figueroa@ieo.es

${ }^{2}$ BioSciences Department, Rice University, Houston, TX, USA, emails: lih2@rice.edu, ac53@rice.edu

${ }^{*}$ Corresponding authors

\section{ABSTRACT}

Dinoflagellates in the family Symbiodiniaceae are obligate endosymbionts of diverse marine invertebrates, including corals, and impact the capacity of their hosts to respond to climate change-driven ocean warming. Understanding the conditions under which increased genetic variation in Symbiodiniaceae arises via sexual recombination can support efforts to evolve thermal tolerance in these symbionts and ultimately mitigate coral bleaching, the breakdown of the coral-Symbiodiniaceae partnership under stress. However, direct observations of meiosis in Symbiodiniaceae have not been reported, despite various lines of indirect evidence that it occurs. We present the first cytological evidence of sex in Symbiodiniaceae based on nuclear DNA content and morphology using Image Flow Cytometry, Cell Sorting and Confocal Microscopy. We show Symbiodiniaceae cells undergo gamete conjugation, zygote formation and meiosis within a dominant reef-building coral in situ. On average, sex was detected in $1.5 \%$ of the cells analyzed ( $N=10.000-40.000$ cells observed per sample in a total of 20 samples obtained from 3 coral colonies). We show that meiosis follows a two-step process described in other dinoflagellates, in which diploid zygotes form dyads during meiosis I and triads and tetrads as final products of meiosis II. This study sets the stage for investigating environmental triggers of Symbiodiniaceae sexuality and can accelerate the assisted evolution of a key coral symbiont in order to combat reef degradation. 


\section{INTRODUCTION}

Reef-building corals and other marine invertebrates establish obligate symbioses with a diverse group of dinoflagellates in the family Symbiodiniaceae (reviewed $\mathrm{in}^{1,2}$ ). This symbiosis can be disrupted by environmental stressors including elevated sea surface temperatures (SSTs) and increased UV radiation, resulting in bleaching - the mass loss of Symbiodiniaceae cells and/or chlorophyll from the hostand frequently, host mortality ${ }^{3,4}$. Thermal stress due to anthropogenic climate change is recognized as the leading cause of coral reef degradation ${ }^{5-7}$. Despite this, the onset of coral bleaching from 2007 to 2017 occurred at significantly higher SSTs $\left(+\sim 0.5^{\circ} \mathrm{C}\right)$ than over the decade preceding that period ${ }^{8}$. This suggests that thermally susceptible genotypes may have adapted and/or declined such that the thermal threshold for bleaching has increased. As reefs continue to experience thermal stress under committed (and likely additional) warming due to climate change, supporting the assisted evolution of thermal tolerance in Symbiodiniaceae ${ }^{9}$ is critical to increasing reef resilience ${ }^{10}$ and contributing to the restoration of ecologically and economically valuable ecosystems ${ }^{11}$.

The most direct mechanism for adaptation to environmental challenges is $\operatorname{sex}^{12,13}$. Sexual recombination of parental genotypes during meiosis promotes new (and potentially beneficial) genetic combinations in offspring, the basic prerequisite for evolution via natural selection. Indeed, various field observations and experimental evolution studies across diverse taxa have documented that stressful or novel environments can select for higher levels of sexuality ${ }^{14}$, and microorganisms, including Symbiodiniaceae, are predicted to have a high adaptive capacity in selective environments ${ }^{15,16}$. Meiosis is the hallmark of sex, consisting of two nuclear divisions (karyokinesis) and one simultaneous or two successive cytoplasmic divisions (cytokinesis). Recombination in meiosis 'remixes' genetic material from both parents to increase genetic variation in the progeny, in contrast to mitosis-the division typical of ordinary cell growth-where daughter cells have the same number and kind of chromosomes as the parent cell ${ }^{17}$.

More than $10 \%$ of the approximately 2.000 known marine dinoflagellate species produce cysts and are thought to undergo facultative sex as part of their life cycle ${ }^{18}$. In these dinoflagellates, reproduction is primarily asexual (through mitosis, Fig. 
1A), but sex can be induced within a subset of cells in a population under certain environmental conditions. Foundational studies, dating back to the 1970s, linked dinoflagellate sexuality to the formation of highly resistant, benthic stages ('resting cysts'), considered a mechanism for surviving harsh environmental conditions ${ }^{19}$. When resting cysts germinate, meiosis results in the release of novel genotypes that are potentially better adapted to local conditions. Although dinoflagellate sex was first proposed to be rare in nature ${ }^{20}$, research over the last decade revealed that sex in these microeukaryotes is a relatively frequently and flexibly utilized reproductive mechanism. The capacity for sex in dinoflagellates is also now recognized as independent of a species' ability to form resting cysts (see reviews by ${ }^{21,22}$ ). Initial studies of Crypthecodinium cohnii suggested that dinoflagellates could undergo only a one-step meiosis ${ }^{23}$ (Fig. 1B.1), but later works on different species consistently reported the existence of a two-step meiotic process ( ${ }^{24}$ and references therein). In two-step meiosis, there is a delay in meiosis II: a single division occurs in the zygote, whereas the second division takes place at postzygotic stages (Fig. 1B.2). Despite these advances, sexuality remains difficult to identify in most dinoflagellate species due to (i) morphological similarities between sexual and vegetative stages; and (ii) the potential for co-occurrence of 2C DNA content stages derived from both mitosis (haploid) and gamete fusion (diploid) within the same population of cells. Given this, a general consensus has emerged that the detection of a 4-fold DNA content stage, which is formed during meiosis (but not mitosis), is key to identifying sex in dinoflagellates ${ }^{25-29}$.

A growing body of molecular evidence shows that Symbiodiniaceae possess functional sexual machinery, and thus suggests that these key coral reef symbionts can reproduce sexually. Indirect evidence for sexual reproduction in this group includes: i) the existence of a sufficient inventory of essential Symbiodiniaceae meiotic genes ${ }^{30,31}$, as well as genes related to gamete formation ${ }^{32}$; and ii) population-level genetic signatures $\mathrm{s}^{33-36}$ and codon usage trends ${ }^{32}$ most parsimoniously interpreted as arising from meiotic recombination. Upregulation of meiosis-related genes has also been documented to occur under thermal stress ${ }^{37,38}$. This temperature-associated regulation suggests that sexual reproduction may be key for the adaptation of Symbiodiniaceae under current warming trajectories, driven by climate change. 
In contrast to this growing body of evidence, genomic evidence for the absence of canonical synaptonemal complex (SC), as well as for a reduced set of cohesin complex genes ${ }^{32}$, have been reported from this dinoflagellate family. The synaptonemal complex (SC) mediates the pairing of homologous chromosomes during the early stages of meiotic prophase I and cohesin proteins play a role in sister chromatid cohesion. However, the absence of the SC and reduction of cohesin complex genes does not preclude meiotic capability in Symbiodiniaceae; similar patterns have been reported in other dinoflagellates known to be sexual ${ }^{32}$.

Despite strong molecular evidence of sexual reproduction in Symbiodiniaceae, no direct cytological proof for fertilization and meiosis in this group have been available. The first cytological descriptions of Symbiodiniaceae (which was previously recognized as a single genus, Symbiodinium ${ }^{2}$ ) life cycle stages ${ }^{39}$ indicated the existence of motile gymnodinoid zoospores and vegetative cells (the dominant, non-motile stage). Freudenthal ${ }^{39}$ observed that vegetative cells (haploid) either divide by binary fission or form cysts, which are characterized by a thicker wall (Fig. 2A). Cysts could divide or turn into a zoosporangium, which could either release a swimming gymnodinoid zoospore or remain as a non-motile spore (aplanospores, Fig. 2A). In cultures described as "old", which could indicate nutritional deficiencies, cysts were observed to contain dividing autospores (according to their external morphology, typically two and rarely four). Under certain conditions (not clarified, although the cultures used were clonal), cysts could even give rise to multiple cells resembling a process of gametogenesis. However, morphologies related to gamete conjugation were not detected ${ }^{39}$. Fitt and Trench $^{40}$ subsequently argued that the term "coccoid stage" should be used to describe the non-motile form of Symbiodiniaceae (as opposed to "cyst"). This is because "cyst" in dinoflagellates is usually related to a dormant (non-active), resistant (thick wall) stage, whereas "coccoid stage" can be used independently of a cell's metabolic activity or cell wall thickness (a highly variable character). Instead, the haploidy of the coccoid (vegetative) stage was considered key to sexuality by Fitt and Trench ${ }^{40}$, who argued that if the coccoid stage was haploid, doublets and emerging motile cells result from a mitotic division, whereas tetrads could represent sexual stages resulting from meiotic division. A summary of this proposed life cycle ${ }^{41}$ is shown in Fig. 2A. Later works based on nuclear 
reconstructions ${ }^{42}$ and microsatellites ${ }^{43}$ supported this hypothesis of a sexual cycle in Symbiodiniaceae, as they provided molecular evidence of haploidy in vegetative stages of diverse species in Breviolum (a Symbiodiniaceae genus formerly known as 'Symbiodinium clade $\mathrm{B}^{2,43}$ ). Previous work has shown that algal endosymbionts of other dinoflagellate taxa (i.e., Peridinium balticum) can sexually reproduce ${ }^{44}$, providing general support for hypothesized sexuality in intracellular symbionts. Although seminal, previous cytological descriptions of the Symbiodiniaceae life cycle and potential sexual stages remain incomplete (e.g., without evidence of gamete fusion) and lack supporting nuclear images and DNA content analyses ${ }^{39,40}$; additional cytological analyses of Symbiodiniaceae life stages are necessary to directly demonstrate sexuality in this key dinoflagellate family of reef symbionts.

Here, we provide new cytological evidence for sexuality in Symbiodiniaceae, focusing on nuclear processes (regardless of motility stage). A combination of flow cytometry techniques (image flow cytometry and sorting) and high-resolution confocal microscope imaging were conducted on Symbiodiniaceae populations fixed within the tissues of a dominant coral genus (Pocillopora spp.) sampled from a South Pacific reef. Our work provides the first direct cytological evidence of meiosis and gamete function in Symbiodiniaceae and suggests that sexual reproduction can occur in hospite under natural conditions. These findings open the door to exploring the conditions that promote sex, as well as potential variation in sexual recombination rates, among Symbiodiniaceae species.

\section{RESULTS}

1. Image Flow Cytometry (IFC): Some single Symbiodiniaceae cells had higher DNA content than is required for a mitotic division

Cells were classified into different DNA content groups according to the regions previously defined, based on their external morphology and the number of nuclei observed. On average, the (>2C-4C) DNA content group represented a low percentage of samples: typically $<1 \%$ of the cells observed (mean of $0.7 \pm 1.0$ ) with a maximum of 3.3\% of cells per sample (Table 1, Fig. 3B: IFC). No significant differences between heat-treated versus control samples, or based on sampling time were detected. " $\mathrm{C}$ " DNA content cells had only one roundish nucleus (Fig. 3C), whereas in " $2 \mathrm{C}$ " DNA 
content cells, one or two nuclei (Fig. 3D top and bottom rows, respectively) were observed. In "2C-4C" DNA content cells, one, two or three/four nuclei (Fig. 3E-top, middle and bottom rows, respectively) were identified.

2. Cell sorting and confocal microscopy: Clarifying the fine morphology of nonmitotic cells

The percentage of cells in the $(>2 C-4 C)$ region based on cell sorting was higher than the IFC results, ranging from 0.1 to $4.7 \%$ (mean of $1.61 \pm 1.26$ ), although typically below 1.5\% (Table 1, Fig. 3B: Sorting). As with the IFC analyses, no significant differences between heat-treated versus control samples, or based on sampling time were found. Sorted cells in each DNA content group were photographed and analyzed morphologically using confocal microscopy as described below.

\subsection{Cells in "1C" DNA content gate}

Cells in the " $1 C$ " DNA content region had relatively round outer morphologies, with an ovoid to trapezoid nucleus $(N)$ in which condensed chromosomes were visible; the nucleus was in a peripheral position (Fig. 4). In most " $C$ " cells, a single pyrenoid (PY) was observed as a round depression under transmitted light. Each cell also contained a single accumulation body $(A B)$ that was irregular in size and shape; accumulation bodies were slightly stained by PI (Fig. 4A-B, arrows). Individual chromosomes could sometimes be distinguished (Fig. 4C); chromosome sizes were highly variable (Fig. $4 C^{\prime}$ ).

\subsection{Cells in " $2 \mathrm{C}$ " DNA content stage}

" $2 C$ " DNA content cells had either 1 or 2 nuclei. " $2 C$ " cells with one nucleus were either classified as part of the mitotic cycle (Fig. 5) or non-mitotic (and therefore, potentially meiotic, Fig. 6) according to the number of pyrenoids and accumulation bodies they contained. Within the mitotic cycle (Fig. 5), cells with 1 nucleus (Fig. 5A-B) varied greatly both in terms of the shape of the nucleus and in the outer morphology of the cell. Most cells had an elongated outer morphology and nucleus, with one pyrenoid (arrow) and one accumulation body (arrow head, Fig. 5A-B). Cells with these characteristics were interpreted as replicating their DNA prior to mitotic division. Progression of mitosis was evident in two-nuclei " $2 \mathrm{C}$ " cells (e.g., Fig. $5 \mathrm{C}-\mathrm{F}$ ) based on the presence of an equatorial constriction which is formed after nuclear division. As division progresses, the pyrenoid is shared (Fig. 5D, arrow), to later appear clearly in 
each cell (Fig. 5E-F, arrows), whereas the accumulation body remains single and unshared (Fig. 5E, arrowhead). At the final mitotic stage, nuclei were positioned either opposite or adjacent to each other (Figs. 5E and F, respectively). In the other group of " $2 \mathrm{C}$ " cells with a single nucleus, classified as non-mitotic cells (Fig. 6), two pyrenoids and accumulation bodies were observed, and the outer morphologies suggested the existence of two newborn cells (splitting apart) or two fusing cells (i.e., mating). Two accumulation bodies (e.g., Fig. 6A-C arrowheads) and two pyrenoids (e.g., Fig. 6D, arrows) were observed in these cells.

\subsection{Cells in (>2C-4C) DNA content region}

Cells in (>2C-4C) DNA content positions could have either one, two, three or four nuclei. In cells with one nucleus, the nucleus was usually irregularly shaped and its chromatin appeared uncondensed (Fig. 7A-B). Two pyrenoids were clear in some cells (e.g., arrowheads in Fig. 7A), and a central nuclear channel (cytoplasmic channel) was occasionally visible (e.g., Fig. 7B arrow). In two-nuclei cells with (>2C-4C) DNA content, the nuclei often differed from each other in size and shape, although they exhibited the equatorial furrow typical of dividing " $2 \mathrm{C}$ " DNA content cells (Fig. 7C-F, arrows). In three-nuclei cells (Fig. 8, nuclear staining), which are hereafter termed "triads", either two lobes (Fig. 8A-B, transmitted light) or three lobes (Fig. 8 C-D, transmitted light) were observed in the outer cell morphology. Three-lobed triads were characterized by having one bigger lobe and two smaller ones, whereas in two-lobed triads, one of the lobes was typically undergoing division, as evidenced by the existence of an equatorial furrow within it (Fig. 8 A-B, transmitted light, arrows). Four-nuclei cells (Fig. 9), which are hereafter termed "tetrads", either had two or three lobes in their outer morphology (Fig. 9, transmitted light). For example, Fig. 9A (transmitted image) depicts a tetrad in which only two lobes were observed, and each lobe contained a middividing furrow (arrows). In the tetrads shown in Fig. 9B-D, two of the lobes had no dividing furrow, whereas the third lobe was bigger than the other lobes and displayed a longitudinal furrow separating the two nuclei within (arrow).

\section{DISCUSSION}

Foundational studies previously generated evidence delineating much of the Symbiodiniaceae life cycle, and strong molecular evidence indirectly supported the 
existence of a sexual phase in this group of dinoflagellates. However, cytological proof of sexual reproduction in Symbiodiniaceae was still needed to advance our understanding of the basic biology of the ecologically and economically valuable Symbiodiniaceae-coral mutualism, and to catalyze subsequent research into when, where, and how sex occurs in this dinoflagellate group. This study is the first to apply cutting edge approaches (IFC, sorting and confocal analyses) to identify Symbiodiniaceae cells with DNA content and nuclear processes that can definitively be interpreted as sexual activity. This first description of a complete nuclear progression compatible with sex in Symbiodiniaceae, ranging from the identification of putative zygotes to the formation of dyads, triads and tetrads, aligns with a meiotic two-step process already described in other dinoflagellates (e.g. ${ }^{29,45,46}$ ). Below, we highlight key DNA content and cell morphology observations that allow us to establish differences between mitosis and meiosis in Symbiodiniaceae cells, compare our hypothesis for sex in Symbiodiniaceae to the sexual stages reported in other dinoflagellate species, and highlight outstanding questions regarding the conditions that promote Symbiodiniaceae sex.

Identifying sexual stages: Key differences between mitotic and meiotic cells Image flow cytometry (IFC) indicated that most of the Symbiodiniaceae cells processed in this study fell into a single group representing the vegetative stage, characterized by low DNA content (" $1 C^{\prime}$ ", haploid) and a single, oval to round-ish nucleus. As recently shown in other dinoflagellate species ${ }^{47,48}$, close examination of the haploid cells with confocal microscopy showed that chromosomes were not all identical as previously thought ${ }^{49}$, but in fact, highly variable in size (e.g., Fig. $4 C^{\prime}$ ). Other single nucleus cells fell between " $1 C$ " and " $2 C$ " DNA contents and were interpreted to be replicating their DNA as part of the mitotic cycle ("S" phase). However, some cells with a single nucleus had a DNA content higher than $2 \mathrm{C}$; these cells were consistent with a replicating zygote in meiosis I during a two-step meiosis (Fig. 1B.2).

Following a similar dichotomy to the cells with one nucleus, cells with two nuclei could have either 2C DNA content and be in a mitotic cycle, or have a DNA content $>2 \mathrm{C}$ and be in a non-mitotic cycle. The two nuclei of cells in this latter group 
varied in size, shape and chromatin condensation state; such cells were interpreted as precursors to a triad stage (i.e., cell with three nuclei). To distinguish cells that were part of this non-mitotic sequence, cells with two nuclei and DNA content between " $2 \mathrm{C}$ " and " $4 \mathrm{C}$ " were considered dyads, as opposed to what we will simply call "mitotic coccoid stages". Cells with three and four nuclei (triads and tetrads, respectively) were also detected. Although the morphologies of these stages were difficult to analyze in the IFC images (Fig. 3D-E), such cells could be examined at higher magnification using sorting and confocal microscopy. The variability observed in tetrad morphology (Fig. 9) indicates these cells were dividing stages derived from triads (Fig. 8), in what we interpret to be a delayed Meiosis II. Taken together, we infer that the observed Symbiodiniaceae tetrad cells were undergoing two-step meiosis (Fig. 1B.2); this reproductive strategy has been observed in most studied dinoflagellates. For example, Prorocentrum micans and Prorocentrum minimum form tetrads as a final meiotic product $^{29}$. Additionally, asynchronous divisions of the zygote in these Prorocentrum species also lead to the formation of triads ${ }^{29}$. It should be noted that some free-living dinoflagellates (e.g., members of the genus Alexandrium) produce chains of cells during two consecutive mitotic divisions. In these Alexandrium species, cell chains are formed frequently and are readily detectable in any growing culture. Since Symbiodiniaceae do not form such chains in culture, it is unlikely that the low percentage of tetrad cells observed in our study represent a mitotic, regular division process. Instead, this study documents Symbiodiniaceae cells with (>2C-4C) DNA content and a single nucleus that have a morphology consistent with a replicating zygote-such a cell stage is not possible within a mitotic cycle and thus constitutes the first direct proof of meiosis in this dinoflagellate family.

If Symbiodiniaceae engage in sexual reproduction, albeit at low levels within the observed cell populations, then other sexual stages, such as zygotes, should also be observable. Here, we briefly review how mitosis proceeds in Symbiodiniaceae; cells diverging from this process can be recognized as zygotes. According to Freudenthal ${ }^{39}$, during the mitotic division process, all cellular inclusions are equally distributed among the daughter cells with the exception of the accumulation body, which persists as a single unit in the parent cell. Karyokinesis occurs followed by cytoplasmic division, which is initiated by the formation of an equatorial zone of constriction. Following 
mitotic division, each new daughter cell produces a new cell wall within the old cell wall of the parent cell ${ }^{50,51}$. The old cell wall material is then degraded via an unknown process $^{52}$, releasing the daughter cells. Based on this description of mitosis, only one accumulation body should be present in mitotically dividing cell stages (as shown in Fig. 5). Some of the $2 \mathrm{C}$-single nucleus cells in this study were therefore identifiable as zygotes because they contained two accumulation bodies (Fig. 6A-C); such cells could not have been undergoing mitotic division.

The nuclear morphology and pyrenoid count of some cells also allowed zygotes to be distinguished from mitotically dividing cells. For example, 2C-two nuclei cells with duplicated pyrenoids would only be observed at advanced stages of mitotic division; such cells were frequently detected in our study (e.g., Fig. 5C-D). However, we also observed cells that contained only one " 2 C" DNA content nucleus but had two well-developed pyrenoids (Fig. 6D, Fig. 7A); such cells could not have been undergoing mitosis and were interpreted as fusing gamete products or early stage zygotes (these differences in accumulation bodies and pyrenoids are summarized in Fig. 2B.2 mitotic stage versus $2 \mathrm{~B} .3$ zygote).

Sexual stages of Symbiodiniaceae are similar to those reported in free-living dinoflagellates

In free-living dinoflagellates, the identification of zygotes in non-resting stage cells (planozygotes) has been impeded due to the high morphological similarity between planozygotes and mitotic cells. In past studies, the number of flagella was considered the hallmark of a zygote (although this characteristic is unreliable due to the weak nature of flagella under fixation). Number of flagella is inapplicable to Symbiodiniaceae, however, since this family alternates between mobile and coccoid stages (Fig. 2A), the latter of which lacks flagella. Therefore, the key to morphological discrimination of zygotes in Symbiodiniaceae (and other dinoflagellates in non-resting stages) lies in differentiating features of sex from mitosis, either during nuclear fusion of gametes or the meiotic process. The process of zygote formation we posit for Symbiodiniaceae here is very similar to that observed in other dinoflagellates. For example, during gamete fusion in the naked dinoflagellates Gymnodinium catenatum and Gymnodinium nolleri, karyokinesis occurs first, and, during the process, one 
gamete nucleus migrates to the position of the other, and they fuse. This occurs while the cell wall is in early stages of fusion, allowing two fusing cytoplasms to be distinguished $^{45,46}$ (Fig. 10, first row). In other species, such as Prorocentrum micans, the process looks similar at the nuclear level, but the cytoplasms never fuse, and instead, one of them degenerates ${ }^{26}$. Early stages of meiosis in Gymnodiniaceae are characterized by a big and round-ish zygotic nucleus that changes into a bi-lobed form with a central 'cytoplasmic channel', and a DNA-decondensed state in which chromosomes appear thinner (Fig. 10, second row). In dinoflagellates, chromosome segregation occurrs via binding to the nuclear envelope surrounding the cytoplasmic channels and microtubule bundles ${ }^{53}$. Although the formation of cytoplasmic channels was first described during mitosis ${ }^{54,55}$, it was later also confirmed to occur during meiosis. Specifically, a main channel centrally positioned during meiosis I is often visible via conventional fluorescence microscopy ${ }^{45,46}$. Given this, some of the onenucleus Symbiodiniaceae cells with (2C-4C) DNA content recorded here (Fig. 7A-B) could represent zygotes in early Meiosis I.

Some characteristics and processes described here for Symbiodiniaceae have also been reported for members of the plant kingdom. For example, the final product of male meiosis in flowering plants is a tetrad of haploid microspores enclosed in a polysaccharide cell wall, and meiosis I often leads to the formation of dyads. Each dyad can divide again to form tetrads through an asynchronous meiosis II division ${ }^{56}$. In Arabidopsis, two nuclear divisions occur before simultaneous cytokinesis yields a tetrad of haploid cells. Additionally, in some Arabidopsis mutants, cell divisions are delayed, resulting in the formation of abnormal intermediates, most frequently dyad meiotic products ${ }^{57}$.

The hypothesized process for gamete conjugation proposed here aligns with previous observations of Symbiodiniaceae by Freudenthal ${ }^{39}$ and Fitt and Trench ${ }^{40}$. These researchers indicated that during Symbiodiniaceae cell division, karyokinesis (nuclear division) occurs first, and later an equatorial zone of constriction in the cytoplasm separates the two daughter cells, which split pyrenoids but not accumulation bodies. As occurs in other dinoflagellate species (e.g. $\left.{ }^{45,46}\right)$, we propose that nuclear fusion is faster than cytoplasmic fusion during the process of gamete conjugation, given the existence of cells with elongated external shapes and duplicated 
pyrenoids and accumulation bodies but a single " 2 C" DNA content nucleus; such cells further corroborate ongoing gametogenesis and zygote formation. Thus, the hypothesized Symbiodiniaceae life cycle (summarized in Fig. 2A) put forward by initial, foundational works ${ }^{39,40}$ constitutes the foundation of our updated life cycle (Fig. 2B-C,

Supp. Fig. 1). This study documents the entire meiotic process in Symbiodiniaceae, and includes: i) the novel observation of (2C-4C) DNA content cells with a single nucleus (i.e., direct proof of meiosis); ii) the identification of previously unpredicted intermediate stages, including dyads and triads; and iii) the first images of tetrads, which had a relatively linear morphology, compared to the previously described coccoid morphology (Fig. 2B4 and Fig. 9 vs Fig. 2A4, respectively). Integrating our observations with foundational works, we provide a revised proposed life cycle for Symbiodiniaceae in supplementary figure S1.

\section{Outstanding questions regarding Symbiodiniaceae sex}

Both techniques (IFC and conventional flow cytometry) applied in this study indicated that sex occurs rarely in Symbiodiniaceae in hospite (typically occurring in less than $1 \%$ of cells observed in a sample and at a maximum of $5 \%$ of cells); sex was only detectable using high resolution imaging following cell sorting. Conventional flow cytometry has a lower capacity to discriminate cells from other fluorescent particles or aggregates; this is likely why the technique reported a slightly higher percentage of cells with (2C-4C) DNA content than IFC analyses (Table 1). Regardless, findings from both techniques agree with previous molecular analyses that indicated Symbiodiniaceae display a mixed reproductive strategy, which is mainly asexual with occasional to frequent $\operatorname{sex}^{35}$. In free-living dinoflagellates, sex also originally appeared to occur rarely and as a last resort in case of severe nutrient deficiency ${ }^{20}$. However, later studies concluded that sexual reproduction in these dinoflagellates is probably more common and flexible in nature than previously thought, although induced under species-specific environmental conditions ${ }^{21,22}$. Now that sexual stages are confirmed for Symbiodiniaceae, we can investigate the environmental factors promoting sex and the physiological details of the sexual stages documented in this study. Although no relationships between sexuality and time of day or temperature stress were detected in the present study, more comprehensive analyses are needed to investigate their 
possible role as triggers of sexuality (Fig. 11). For example, certain experimental designs have previously missed meiosis in other dinoflagellates, since this process can be strongly entrained with specific points in the diel cycle ${ }^{28}$. The abiotic triggers of sexuality and other research directions that are likely to advance our understanding of the role and constraints on Symbiodiniaceae sex in nature are summarized as outstanding questions in Figure 11. Pursuing such lines of inquiry will shed light on the evolutionary implications that may accompany the induction of new genetic diversity in Symbiodiniaceae via enhanced sexuality, including the potential for rapid symbiont adaptation to thermal stress ${ }^{58}$.

\section{Conclusion}

This study is the first to categorically demonstrate sexual reproduction in Symbiodiniaceae, establishing a foundation from which to explore the potential role of symbiont evolution in coral resilience to global change. Based on DNA content and morphological evidence, we propose that Symbiodiniaceae species may follow the same two-step meiotic process described for other dinoflagellates, in which the first meiotic division produces a dyad of cells, whereas the second division produces an intermediate triad state, with meiosis II ultimately resulting in a tetrad stage of haplontic cells. Beyond basic biology, understanding sexuality in Symbiodiniaceae can advance experimental evolution work on this group, with the goal of enhancing the capacity of coral holobionts to cope with warming ocean temperatures and other stressors under rapid global change.

\section{MATERIAL AND METHODS}

Symbiodiniaceae sampling and identification

Three colonies (separated by $\sim 5 \mathrm{~m}$ on the reef and likely representing distinct genotypes) of Pocillopora species complex ${ }^{59}$ were collected from the forereef on the north shore of Mo'orea, French Polynesia during the dry season (July 2019). Colonies were confirmed to contain symbionts in the genus Cladocopium based on restriction fragment length polymorphisms (RFLPS) of the Symbiodiniaceae Large Subunit (LSU, 28S-like) rDNA. 
Restriction enzyme digests of LSU rDNA PCR amplicon products were conducted with Taq1 and Hha1 (New England BioLabs) following ${ }^{60}$. Colonies were then split in half and maintained in flow-through seawater aquaria; half of each colony was subjected to an elevated temperature treatment $\left(\sim 3^{\circ} \mathrm{C}\right.$ above ambient), while the other half was maintained at ambient temperatures. To maximize the chance of detecting meiotic events, samples were collected and preserved from both the heated and ambient tank intermittently throughout the day and night over a three-day period (Table 1). For each sample, one branch $\left(\sim 5 \mathrm{~cm}^{2}\right)$ was removed from a given coral colony, airbrushed using $0.22 \mu \mathrm{m}$ filtered seawater, and homogenized using a Fisherbrand 150 handheld homogenizer (Waltham, Massachusetts). The homogenate was filtered through $70 \mu \mathrm{m}$ mesh and fixed to a final concentration of $3 \%$ formalin. Fixed cells were concentrated by centrifugation and stored at $4^{\circ} \mathrm{C}$ until further processing. Details of the samples analyzed in this study ( $n=6$ time points and 20 replicates total from 3 coral colonies) are provided in Table 1.

\section{Flow cytometry analyses}

Imaging Flow Cytometry (IFC). Samples were centrifuged at $7000 \times \mathrm{g}$ for $5 \mathrm{~min}$ and the pellet resuspended in $2.5 \mathrm{~mL}$ of cold methanol, where they were stored for at least $12 \mathrm{~h}$ at $4^{\circ} \mathrm{C}$ to facilitate pigment extraction. Cells were then washed in PBS $(\mathrm{pH} 7$, Sigma-Aldrich, St. Louis, MO, USA) using the same centrifugation conditions, and the resulting pellet was resuspended in a staining solution consisting of $300 \mu \mathrm{L}$ of propidium iodide (Sigma-Aldrich, $60 \mu \mathrm{g} \cdot \mathrm{mL}^{-1}$ ) and $30 \mu \mathrm{L}$ of RNaseA (Sigma-Aldrich, $100 \mathrm{mg} \cdot \mathrm{mL}^{-1}$ in PBS) for at least $2 \mathrm{~h}$ in darkness before analysis. Samples were washed in PBS twice right before being run on a Flow Sight image flow cytometer (Amnis, Seattle, WA, USA), with two lasers, emitting at 488 and $405 \mathrm{~nm}$. The samples were run at low speed and data were acquired until 50,000-70,000 total events were recorded. The software Ideas 6.0 (Amnis Corporation) was used to analyze DNA fluorescence distributions and the morphologies of cells in the images obtained.

Image and cell cycle analyses by IFC. A general template for focused Symbiodiniaceae cells was created, in which unfocused cells and aggregates were eliminated. The gradient Root Mean Square (RMS) feature was used to select focused cells, which have a higher gradient than unfocused cells ${ }^{61}$. Aggregates were eliminated 
by visually plotting cellular area versus nuclear fluorescence. Each cell-cycle phase was delimited by means of a histogram of propidium iodide (PI) fluorescence using 488 laser excitation. Different regions were defined according to PI-DNA fluorescence: the lowest DNA content coincided with the main peak of the population that was clear in all samples and was named " $1 C^{\prime}$ " (Fig. 3A). This peak indicates the basic DNA content of Cladocopium cells examined. A region with the same width as " $1 C$ " was centered at $2 x$ the Geometric mean of the $1 \mathrm{C}$ population (based on PI fluorescence, channel 4) and named " $2 \mathrm{C}$ " (Fig. 3A). Cells detected in the " $2 \mathrm{C}$ " region could be ready to undergo mitosis, or be zygotes (Fig. 1). The region in between " $1 \mathrm{C}$ " and " $2 \mathrm{C}$ " was termed " $\mathrm{S}$ " phase (Fig. 3A); cells in this region were interpreted to be in the DNA synthesis phase. A final region was established that ranged from the end of the " $2 \mathrm{C}$ " region to the cells with the highest detected DNA fluorescence, which had approximately " $4 C$ " mean positions. This region was called " $2 \mathrm{C}-4 \mathrm{C}$ " (Fig. 3A) and could include cells ready to undergo two-step meiosis (Fig. 1B.2). Additionally, regardless of the number of nuclei they contained, cells were classified as "individual" (i.e., one cell observed) or as "in cell chains" (i.e., more than one cell observed) according to the nuclear-aspect ratio (width vs. height of the mask used to more precisely adjust the area to the U-shaped nucleus) and the cell area. The precision of the aspect ratio adjustment was made manually by studying the acquired images. During data collection, between 40.000-70.000 events were acquired in the gating region selected for the Symbiodiniaceae population.

\section{Cell sorting}

Cells were prepared for sorting using the same fixation and staining protocol described above for IFC analyses. Cells were sorted at low speed and in high purity mode on a SH800Z cell sorter (Sony Biotechnology Inc.) equipped with a 488-nm diode laser. Peaks were analyzed using the $\mathrm{SH} 800 \mathrm{Z}$ software, and three regions of DNA content were established as described above in the IFC analyses. The entire sample was sorted to increase the number of rare events following two sorting rounds: First, " $\mathrm{C}$ " and " $2 \mathrm{C}$ " cells were sorted until approximately 5.000 events were sorted into the " $1 C^{\prime \prime}$ population (control). The rest of the sample was sorted in a second round separating " $2 \mathrm{C}$ " from ">2C-4C"cells. For statistical analyses, populations with different DNA content regions 
were analyzed using histograms of PI fluorescence in linear scale using FlowJo ${ }^{\mathrm{TM}}$ 10.7.1 (Becton Dickinson \& Company).

\section{Confocal Microscopy}

Sorted cells were observed using a confocal LEICA SP8 microscope equipped with 3 laser lines $(405,488$ and $552 \mathrm{~nm})$ after mounting the cells on slides using ProLong ${ }^{\text {TM }}$ Gold medium antifade reagent (Invitrogen). The preparations were allowed to rest $1-2 \mathrm{hrs}$ before observations were performed. To improve spatial analyses and decrease the probability of misinterpretation during visual scoring, all images were extracted from 3D videos; all videos are available as Supplementary Files S2-S7. Imaging was performed at $63 x$ or $100 x$ magnification using the super-resolution mode LIGHTNING. Images were optimized for best contrast and brightness, and then analyzed, using LASX software (LEICA Microsystems).

\section{Statistical analyses}

Basic statistics (mean, standard deviation (SD)) and tests for equal means (t-tests) comparing treatment conditions were performed using Past 4.02 software ${ }^{62}$. All tests were performed with a significance level of $p$-value $=0.05$.

\section{REFERENCES}

1. Baker, A. C. Flexibility and specificity in coral-algal symbiosis: diversity, ecology, and biogeography of Symbiodinium. Annu. Rev. Ecol. Evol. Syst. 34, 661-689 (2003).

2. LaJeunesse, T. C. et al. Systematic Revision of Symbiodiniaceae Highlights the Antiquity and Diversity of Coral Endosymbionts. Curr. Biol. 28, 2570-2580.e6 (2018).

3. Glynn, P. W. Coral reef bleaching: facts, hypotheses and implications. Glob. Chang. Biol. 2, 495-509 (1996).

4. Baker, A. C., Glynn, P. W. \& Riegl, B. Climate change and coral reef bleaching: An ecological assessment of long-term impacts, recovery trends and future outlook. Estuar. Coast. Shelf Sci. 80, 435-471 (2008).

5. Hughes, T. P. et al. Global warming and recurrent mass bleaching of corals. 
Nature 543, 373-377 (2017).

6. Hughes, T. P. et al. Global warming transforms coral reef assemblages. Nature 556, 492-496 (2018).

7. Knowlton, N. The future of coral reefs. Proc. Natl. Acad. Sci. U. S. A. 98, 54195425 (2001).

8. Sully, S., Burkepile, D. E., Donovan, M. K., Hodgson, G. \& van Woesik, R. A global analysis of coral bleaching over the past two decades. Nat. Commun. 10, 1-5 (2019).

9. Van Oppen, M. J. H., Oliver, J. K., Putnam, H. M. \& Gates, R. D. Building coral reef resilience through assisted evolution. Proceedings of the National Academy of Sciences of the United States of America vol. 112 2307-2313 (2015).

10. National Academies of Sciences, Engineering, and M. A Research Review of Interventions to Increase the Persistence and Resilience of Coral Reefs. A Research Review of Interventions to Increase the Persistence and Resilience of Coral Reefs (National Academies Press, 2019). doi:10.17226/25279.

11. Duarte, C. M. et al. Rebuilding marine life. Nature vol. 580 39-51 (2020).

12. Becks, L. \& Agrawal, A. F. The evolution of sex is favoured during adaptation to new environments. PLoS Biol. 10, 1001317 (2012).

13. Luijckx, P. et al. Higher rates of sex evolve during adaptation to more complex environments. Proc. Natl. Acad. Sci. U. S. A. 114, 534-539 (2017).

14. Lively, C. M. \& Morran, L. T. The ecology of sexual reproduction. J. Evol. Biol. 27, 1292-1303 (2014).

15. Correa, A. M. S. \& Baker, A. C. Disaster taxa in microbially mediated metazoans: How endosymbionts and environmental catastrophes influence the adaptive capacity of reef corals. Glob. Chang. Biol. 17, 68-75 (2011).

16. Van Oppen, M. J. H., Souter, P., Howells, E. J., Heyward, A. \& Berkelmans, R. Novel Genetic Diversity Through Somatic Mutations: Fuel for Adaptation of Reef Corals? Diversity 3, 405-423 (2011).

17. Lubischer, J. L. The Cell Cycle, Principles of Control. David O. Morgan. Integr. Comp. Biol. 47, 794-795 (2007).

18. Bravo, I. \& Figueroa, R. I. Towards an ecological understanding of dinoflagellate cyst functions. (2014) doi:10.3390/microorganisms2010011. 
19. Pfiester, L. A. \& Anderson, D. M. Dinoflagellate reproduction. in The biology of dinoflagellates (ed. Taylor, F. J. R.) 611-648 (Black Scientific, 1987).

20. Pfiester, L. A. Dinoflagellate Sexuality. Int. Rev. Cytol. 114, 249-272 (1989).

21. Kremp, A. Diversity of dinoflagellate life cycles:facets and implications of complex strategies. in Biological and Geological Perspectives of Dinoflagellates (eds. Lewis, J. M., Marret, F. \& Bradley, L. R.) 197-205 (Geological Society of London, 2017). doi:10.1144/tms5.18.

22. Figueroa, R. I., Estrada, M. \& Garcés, E. Life histories of microalgal species causing harmful blooms: Haploids, diploids and the relevance of benthic stages. Harmful Algae 73, 44-57 (2018).

23. Himes, M. \& Beam, C. A. Genetic analysis in the dinoflagellate Crypthecodinium (Gyrodinium) cohnii: evidence for unusual meiosis. Proc. Natl. Acad. Sci. U. S. A. 72, 4546-4549 (1975).

24. Tillmann, U., Hoppenrath, M. Life Cycle of the pseudocolonial dinoflagellate Polykrikos kofoidii (Gymnodiniales, Dinoflagellata). J. Phycol. 49, 298-317 (2013).

25. Bhaud, Y., Soyer-Gobillard, M.-O. \& Salmon, J. M. Transmission of gametic nuclei through a fertilization tube during mating in a primitive dinoflagellate, Prorocentrum micans Ehr. J. Cell Sci. 89, (1988).

26. Soyer-Gobillard, M.-O., Bhaud, Y. \& Hilaire, S. New data on mating in an autotrophic dinoflagellate, Prorocentrum micans Ehrenberg. Vie Milieu 52, 167175 (2002).

27. Brosnahan, M. L. et al. Complexities of bloom dynamics in the toxic dinoflagellate Alexandrium fundyense revealed through DNA measurements by imaging flow cytometry coupled with species-specific rRNA probes. Deep. Res. Part II Top. Stud. Oceanogr. 103, 185-198 (2014).

28. Figueroa, R. I., Dapena, C., Bravo, I. \& Cuadrado, A. The Hidden Sexuality of Alexandrium minutum: An Example of Overlooked Sex in Dinoflagellates. PLoS One 10, e0142667 (2015).

29. Berdieva, M., Kalinina, V., Lomert, E., Knyazev, N. \& Skarlato, S. Life Cycle Stages and Evidence of Sexual Reproduction in the Marine Dinoflagellate Prorocentrum minimum (Dinophyceae, Prorocentrales). J. Phycol. 56, 941-952 (2020). 
30. Chi, J., Parrow, M. W. \& Dunthorn, M. Cryptic sex in Symbiodinium (alveolata, dinoflagellata) is supported by an inventory of meiotic genes. J. Eukaryot. Microbiol. 61, 322-327 (2014).

31. Liu, H. et al. Symbiodinium genomes reveal adaptive evolution of functions related to coral-dinoflagellate symbiosis. Commun. Biol. 1, 95 (2018).

32. Shah, S., Chen, Y., Bhattacharya, D. \& Chan, C. X. Sex in Symbiodiniaceae dinoflagellates: genomic evidence for independent loss of the canonical synaptonemal complex. Sci. Rep. 10, 1-12 (2020).

33. Baillie, B. K., Belda-Baillie, C. A. \& Maruyama, T. Conspecificity and indo-Pacific distribution of Symbiodinium genotypes (Dinophyceae) from giant clams. J. Phycol. 36, 1153-1161 (2000).

34. LaJeunesse, T. C. Investigating the biodiversity, ecology, and phylogeny of endosymbiotic dinoflagellates in the genus Symbiodinium using the ITS region: In search of a 'species' level marker. J. Phycol. 37, 866-880 (2001).

35. Thornhill, D. J., Howells, E. J., Wham, D. C., Steury, T. D. \& Santos, S. R. Population genetics of reef coral endosymbionts ( Symbiodinium, Dinophyceae). Mol. Ecol. 26, 2640-2659 (2017).

36. Pettay, D. T., Wham, D. C., Pinzón, J. H. \& LaJeunesse, T. C. Genotypic diversity and spatial-temporal distribution of Symbiodinium clones in an abundant reef coral. Mol. Ecol. 20, 5197-5212 (2011).

37. Levin, R. A. et al. Sex, Scavengers, and Chaperones: Transcriptome Secrets of Divergent Symbiodinium Thermal Tolerances. Mol. Biol. Evol. 33, 2201-2215 (2016).

38. Bellantuono, A. J., Dougan, K. E., Granados-Cifuentes, C. \& Rodriguez-Lanetty, M. Free-living and symbiotic lifestyles of a thermotolerant coral endosymbiont display profoundly distinct transcriptomes under both stable and heat stress conditions. Mol. Ecol. 28, 5265-5281 (2019).

39. Freudenthal, H. D. Symbiodinium gen. nov. and Symbiodinium microadriaticum sp. nov., a Zooxanthella: Taxonomy, Life Cycle, and Morphology. J. Protozool. 9, 45-52 (1962).

40. Fitt, W. K. \& Trench, R. K. The relation of diel patterns of cell division to diel patterns of motility in the symbiotic dinoflagellate Symbiodinium 
microadriaticum Freudenthal in culture. New Phytol. 94, 421-432 (1983).

41. LaJeunesse, T. C., Parkinson, J. E. \& Trench, R. K. Symbiodinium. Tree of Life Web Project Version 04 (2012).

42. Blank, R. J. Cell architecture of the dinoflagellate Symbiodinium sp. inhabiting the Hawaiian stony coral Montipora verrucosa. Mar. Biol. 94, 143-155 (1987).

43. Santos, S. R. \& Coffroth, M. A. Molecular genetic evidence that dinoflagellates belonging to the genus Symbiodinium freudenthal are haploid. Biol. Bull. 204, 10-20 (2003).

44. Chesnick, J. M. \& Cox, E. R. Synchronized sexuality of an algal symbiont and its dinoflagellate host, Peridinium balticum (levander) lemmermann. BioSystems 21, 69-78 (1987).

45. Figueroa, R. I., Bravo, I., Garcés, E. \& Ramilo, I. Nuclear features and effect of nutrients on Gymnodinium catenatum (Dinophyceae) sexual stages. J. Phycol. 42, (2006).

46. Figueroa, R. I., Rengefors, K. \& Bravo, I. Effects of parental factors and meiosis on sexual offspring of Gymnodinium nolleri (Dinophyceae). J. Phycol. 42, (2006).

47. Figueroa, R. I., Cuadrado, A., Stüken, A., Rodríguez, F. \& Fraga, S. Ribosomal DNA Organization Patterns within the Dinoflagellate Genus Alexandrium as Revealed by FISH: Life Cycle and Evolutionary Implications. Protist 165, (2014).

48. Cuadrado, Á., De Bustos, A. \& Figueroa, R. I. Chromosomal markers in the genus Karenia: Towards an understanding of the evolution of the chromosomes, life cycle patterns and phylogenetic relationships in dinoflagellates. Sci. Rep. 9, 3072 (2019).

49. Rizzo, P. J. Those amazing dinoflagellate chromosomes. Cell research vol. 13 215-217 (2003).

50. Taylor, D. L. In situ studies on the cytochemistry and ultrastructure of a symbiotic marine dinoflagellate. J. Mar. Biol. Assoc. United Kingdom 48, 349366 (1968).

51. Kevin, M. J., Hall, W. T., McLaughlin, J. J. A. \& Zahl, P. A. Symbiodinium microadriaticum Freudenthal, a revised taxonomic description, ultrastructure. J. Phycol. 5, 341-350 (1969).

52. Wakefield, T. S., Farmer, M. A. \& Kempf, S. C. Revised description of the fine 
structure of in situ 'Zooxanthellae' genus Symbiodinium. Biol. Bull. 199, 76-84 (2000).

53. Soyer-Gobillard, M. O., Ausseil, J. \& Géraud, M. L. Nuclear and cytoplasmic actin in dinoflagellates. Biol. Cell 87, 17-35 (1996).

54. Ris, H. \& Kubai, D. F. An unusual mitotic mechanism in the parasitic protozoan Syndinium sp. J. Cell Biol. 60, 702-720 (1974).

55. Bhaud, Y., Guillebault, D., Lennon, J., Defacque, H., Soyer-Gobillard, M.O., Moureau, H. Morphology and behaviour of dinoflagellate chromosomes during the cell cycle and mitosis. J.Cell Sci. 113, 1231-1239 (2000).

56. Harrison, C. J., Alvey, E. \& Henderson, I. R. Meiosis in flowering plants and other green organisms. J. Exp. Bot. 61, 2863-2875 (2010).

57. Magnard, J. L., Yang, M., Chen, Y. C. S., Leary, M. \& McCormick, S. The Arabidopsis gene tardy asynchronous meiosis is required for the normal pace and synchrony of cell division during male meiosis. Plant Physiol. 127, 11571166 (2001).

58. Wilkinson, S. P., Fisher, P. L., Van Oppen, M. J. \& Davy, S. K. Intra-genomic variation in symbiotic dinoflagellates: Recent divergence or recombination between lineages? BMC Evol. Biol. 15, 46 (2015).

59. Gélin, P., Postaire, B., Fauvelot, C. \& Magalon, H. Reevaluating species number, distribution and endemism of the coral genus Pocillopora Lamarck, 1816 using species delimitation methods and microsatellites. Mol. Phylogenet. Evol. 109, 430-446 (2017).

60. Baker, A., Rowan, R. \& Knowlton, N. Symbiosis ecology of two Caribbean Acroporid corals. in Proceedings of the 8th International Coral Reef Symposium 2 1295-1300 (1997).

61. Marangon, I. et al. Intercellular carbon nanotube translocation assessed by flow cytometry imaging. Nano Lett. 12, 4830-4837 (2012).

62. Hammer, $\varnothing .$, Harper, D. A. T. \& Ryan, P. D. PAST Paleontological Statistics Software Package for Education and Data Analysis. Palaeontologia Electronica, 4, 9 p. - References - Scientific Research Publishing. Paleontol. Electron. 4, 9 (2001). 


\section{ACKNOWLEDGMENTS}

We thank Isabel Ramilo for technical support with sorting flow cytometry sample preparation, and Carsten G.B. Grupstra and Kristen M. Rabbitt for assistance with sample collection. The present work was funded by a national project from the Spanish Ministry of Science and Innovation and the European Community (FEDER) (Project DIANAS-CTM2017-86066-R) to RF, a Lewis and Clark Grant from the American Philosophical Society to LHK, a Wagoner Foreign Study Scholarship to LHK, a U.S. National Science Foundation award (OCE \#1635798) to AC, an Early-Career Research Fellowship (\#2000009651) from the Gulf Research Program of the National Academies of Sciences to AC and start-up funds from Rice University to AC. The content of this work is solely the responsibility of the authors and does not necessarily represent the official views of the Gulf Research Program of the National Academies of Sciences, Engineering, and Medicine. Research was completed under permits issued by the French Polynesian Government (Délégation à la Recherche) and the Haut-commissariat de la République en Polynésie Francaise (DTRT) (Protocole d'Accueil 2005-2020). This work represents a contribution of the Moorea Coral Reef (MCR) LTER Site (NSF OCE 16-37396).

\section{AUTHOR CONTRIBUTIONS}

ASC conceived of the work and designed it with LHK and RIF. Environmental sampling and preliminary sample preparation were performed by LHK, with support from ASC and RIF. IFC, sorting and confocal work, including data analyses and interpretation was done by RIF. All authors wrote and revised the manuscript.

\section{ADDITIONAL INFORMATION}

Supplementary files S1-S7.

The authors declare no competing interest.

\section{DATA AVAILABILITY}

Data supporting the conclusions of this article are included in the article and supplementary files. The datasets analyzed during the current study are available from the corresponding authors upon request. 
FIGURE LEGENDS:

Fig. 1. Differences in DNA content and ploidy state between the mitotic and the meiotic cycle, including the two meiotic processes proposed for dinoflagellates (onestep and two-step meiosis).

Fig. 2. A. Schematic figure of the Symbiodiniaceae life cycle, modified from a depiction by T.C. LaJeunesse (http://tolweb.org/), which was based on (Fitt and Trench 1983). Previously published direct observations include the production of two mobile haploid cells (mastigotes, referred to as 'zoospores' by Freudenthal ${ }^{39}$ ) from mitosis within the coccoid stage (termed 'cysts' or 'aplanospores' by Freudenthal ${ }^{39}$ ), which could behave as isogametes or transform into coccoid stages. The formation of zygotes through gamete fusion, as well as the formation of tetrads (called 'autospores' by Freudenthal ${ }^{39}$ ) via meiosis were hypothesized but not documented. B. Schematic view of the results of the present study in relation to the previously proposed Symbiodiniaceae life cycle (in Fig. 2A). Discriminating morphological features (nuclei, pyrenoids and accumulation bodies) are shown in the sexual stages unless in dyads, triads and tetrads, as these stages are transitory and were found in different evolving grades. C. Confocal images corresponding to the proposed sexual stages depicted in Fig. 2B.

Fig. 3. Imaging Flow Cytometry (IFC) results. A. Summary of the categories and delineation process for classifying Symbiodiniaceae cells according to DNA content (representative data from preliminary sample 10 is displayed) and representative images of each DNA content stage (B-D). B. Percentage (\%) of ( $>2 C-4 C)$ cells in samples analyzed with IFC versus conventional cytometry (Sorting). C. Cells within the 1C DNA content gate that have a single nucleus. D. Cells within the $2 \mathrm{C}$ DNA content gate that have either one nucleus (first row) or two nuclei (second row). E. Cells in the (2C-4C] DNA content group, grouped in rows according to the number of nuclei: 1 (first row), 2 (second row), 3 (third row) and 4 (fourth row).

Fig. 4. Confocal images of cells sorted in the $1 C$ DNA content gate. A-B: representative images of cells showing the pyrenoid (PY, arrow), accumulation body ( $A B$, arrowhead) and nucleus (N). C- $\mathrm{C}^{\prime}$ : Images of a nucleus showing individualized chromosomes with varied shapes and sizes ( $C^{\prime}$ : examples of individual chromosomes are outlined in yellow).

Fig. 5. Confocal images of cells sorted in the 2C DNA content gate and classified as part of the mitotic cycle. Arrows denote the pyrenoids and arrowheads denote the accumulation bodies. In these mitotic cells, only one accumulation body/pyrenoid is detected both in single nucleus cells (A-B) and in pairs which have already duplicated nuclei (C). The pyrenoid is shared in advanced mitotic stages (B) and is duplicated only during more advanced mitotic phases (D-F). 
Fig. 6. Confocal images of sorted cells in the 2C DNA content gate and one single nucleus, interpreted as undergoing the meiotic cycle. These cells have duplicated pyrenoids (arrows) and accumulation bodies (arrowheads).

Fig. 7. Confocal images of cells sorted in the (>2C-4C) DNA content gate that have one nucleus or two nuclei. Chromatin was less condensed in these cells, in which two pyrenoids were detected ( $A$, arrows). A central cytoplasmic channel (cc, bent arrow) was observed in one of these cells (B). Cells with two nuclei (dyads) were considered meiotic and are distinct from two nuclei mitotic cells due to their higher DNA content and the different morphology and shape displayed between both nuclei (C-F). Dividing furrows in dyads are indicated by an arrow.

Fig. 8. Confocal images of cells sorted in the (>2C-4C) DNA content gate that have three nuclei and different numbers of lobes in their external morphology (lobes clearly visible in the transmitted light column). A-B: cells with two lobes, one showing a dividing furrow (arrow); C-D: three lobes.

Fig. 9. Confocal images of cells sorted in the ( $>2 C-4 C)$ DNA content gate that have four nuclei and different numbers of lobes in their external morphology (lobes clearly visible in the transmitted light). $A$ : two lobes with a middle furrow of division each (arrows), B-D: three lobes with a middle furrow of division in the biggest lobe (arrow).

Fig. 10. Comparative images show similarities between sexual stages of Gymnodiniaceae and Symbiodiniaceae. A-C Fusing gametes. A: Putative gamete fusion in Symbiodiniaceae. B-C: Nuclear fusion during syngamy in Gymnodinium catenatum. D-F) Zygotes. D: Putative zygote nucleus in Symbiodiniaceae. E-F: Zygote nuclei in G. catenatum and Gymnodinium nolleri in early meiosis I. A central cytoplasmic channel (arrow, cc) is observed in some zygotes, becoming the bilobed nucleus during Meiosis I. Gymnodiniaceae pictures are original, corresponding to the same time lapse series published in ${ }^{45,46}$.

Fig. 11. Outstanding question box. Summary of important questions for future research. 
Table 1. Details of the Symbiodiniaceae samples analyzed in this study and the \% of DNA content classifications made from each sample. All samples analyzed (Sample ID) originated from three colonies of Pocillopora species complex (Colony ID) collected from the north shore forereef in Mo'orea, French Polynesia during the dry season (July 2019). Pocillopora colonies contained Symbiodiniaceae in the genus Cladocopium. Treatment Condition: C: Control, ambient temperature, $\sim 27^{\circ} \mathrm{C} ; \mathrm{H}$ : Heat stress, $\sim 30^{\circ} \mathrm{C}$. 'Hours after $\mathrm{TO}^{\prime}$ indicates the cumulative hours that corals had been exposed to the treatment condition at the time of sampling. Analysis Type: IFC = Image Flow Cytometry; Sorting= Sorting Flow Cytometry. A minimum of 10.000 cell nuclei were analyzed for DNA content in each sample.

\begin{tabular}{ccccccccc}
\hline $\begin{array}{c}\text { Sample } \\
\text { ID }\end{array}$ & $\begin{array}{c}\text { Colony } \\
\text { ID }\end{array}$ & $\begin{array}{c}\text { Treatment } \\
\text { Condition }\end{array}$ & $\begin{array}{c}\text { Hours } \\
\text { after } \\
\text { T0 }\end{array}$ & $\begin{array}{c}\text { Time } \\
\text { Sampled }\end{array}$ & $\begin{array}{c}\text { Analysis } \\
\text { Type }\end{array}$ & $\mathbf{1 C + S}$ & $\mathbf{2 C}$ & (<2C-4C) \\
\hline $\mathbf{1}$ & A & C & 60 & 0600 & IFC & 92.0 & 8.0 & 0 \\
\hline $\mathbf{2}$ & A & H & 60 & 0600 & IFC & 91.6 & 7.5 & 0.8 \\
\hline $\mathbf{3}$ & A & C & 114 & 1200 & IFC & 94.0 & 5.3 & 0.7 \\
\hline $\mathbf{4}$ & B & H & 60 & 0600 & IFC & 97.5 & 2.5 & 0 \\
\hline $\mathbf{5}$ & B & C & 60 & 0600 & IFC & 96.0 & 3.8 & 0.2 \\
\hline $\mathbf{6}$ & B & C & 114 & 1200 & IFC & 89.8 & 8.6 & 0 \\
\hline $\mathbf{7}$ & B & H & 114 & 1200 & IFC & 82.3 & 16.4 & 1.3 \\
\hline $\mathbf{8}$ & C & C & 60 & 0600 & IFC & 94.8 & 4.8 & 0.4 \\
\hline $\mathbf{9}$ & C & H & 60 & 0600 & IFC & 95.3 & 4.4 & 0.3 \\
\hline $\mathbf{1 0}$ & C & C & 66 & 1200 & IFC & 60.5 & 36.2 & 3.3 \\
\hline $\mathbf{1 1}$ & A & H & 78 & 0000 & Sorting & 88.5 & 7.8 & 2.0 \\
\hline $\mathbf{1 2}$ & A & H & 108 & 0600 & Sorting & 97.9 & 1.9 & 0.1 \\
\hline $\mathbf{1 3}$ & A & C & 108 & 0600 & Sorting & 89.8 & 8.4 & 2.1 \\
\hline $\mathbf{1 4}$ & A & C & 114 & 1200 & Sorting & 89.9 & 9.3 & 1.1 \\
\hline $\mathbf{1 5}$ & B & H & 78 & 0000 & Sorting & 82.9 & 9.5 & 4.7 \\
\hline $\mathbf{1 6}$ & B & C & 108 & 0600 & Sorting & 86.4 & 11.5 & 1.3 \\
\hline $\mathbf{1 7}$ & C & C & 108 & 0600 & Sorting & 94.2 & 4.9 & 0.8 \\
\hline $\mathbf{1 8}$ & C & H & 78 & 0000 & Sorting & 91.9 & 7.4 & 1.3 \\
\hline $\mathbf{1 9}$ & C & H & 108 & 0600 & Sorting & 96 & 3.4 & 0.7 \\
\hline $\mathbf{2 0}$ & C & C & 72 & 1800 & Sorting & 91.1 & 5.9 & 2.0 \\
\hline & & & & & & & & \\
\hline
\end{tabular}


Figures

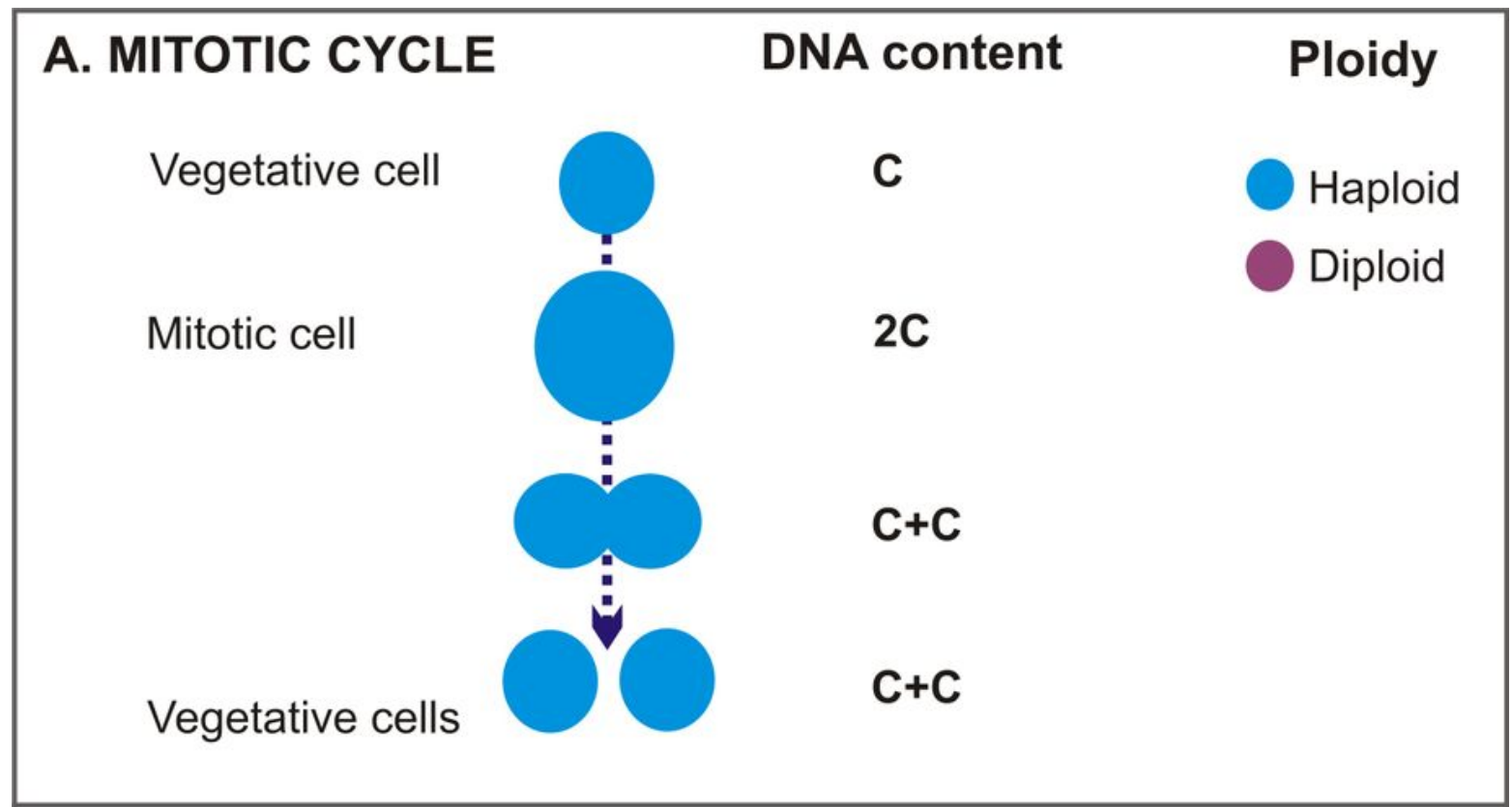

B. MEIOTIC CYCLE

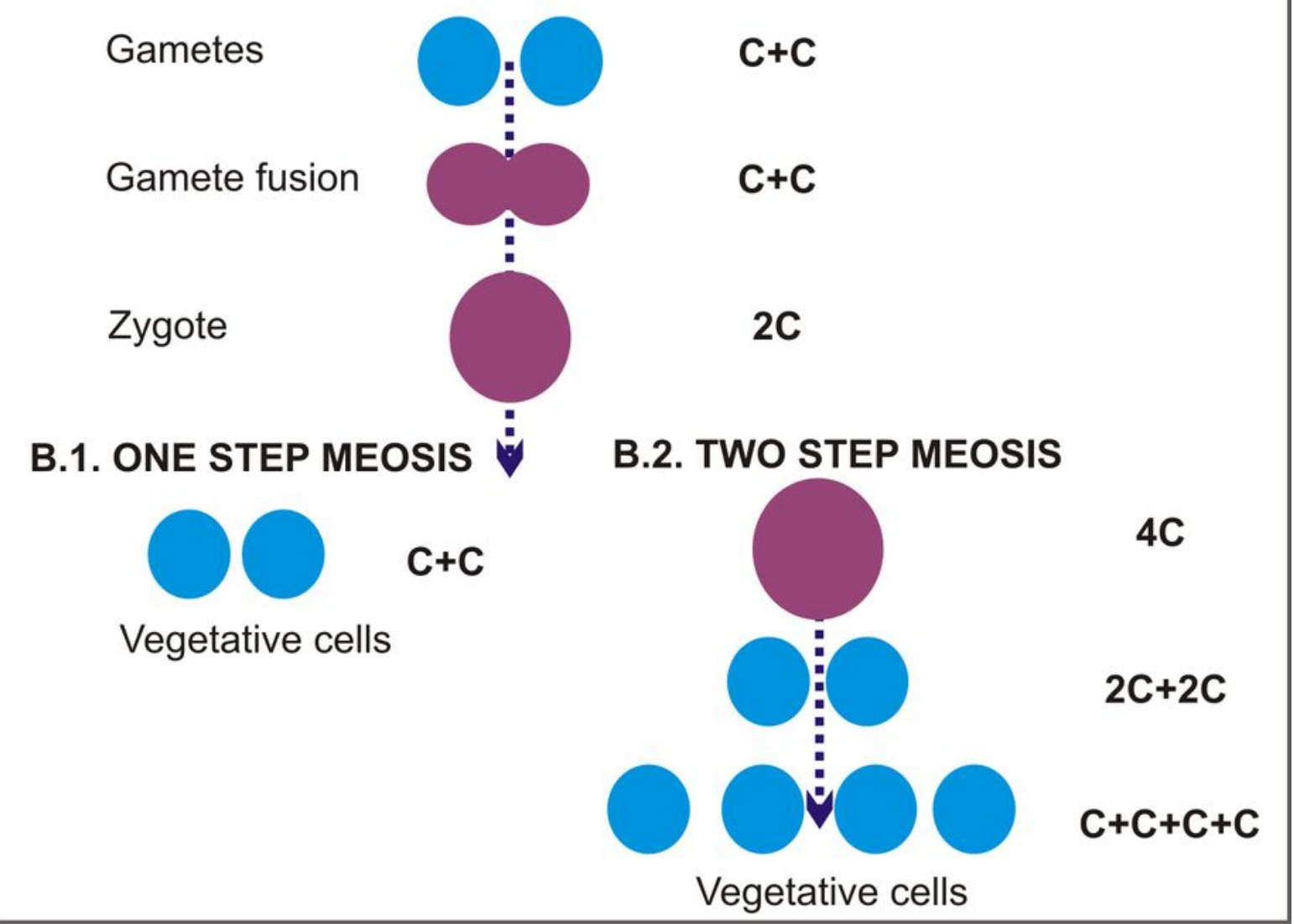

Figure 1

Differences in DNA content and ploidy state between the mitotic and the meiotic cycle, including the two meiotic processes proposed for dinoflagellates (onestep and two-step meiosis). 


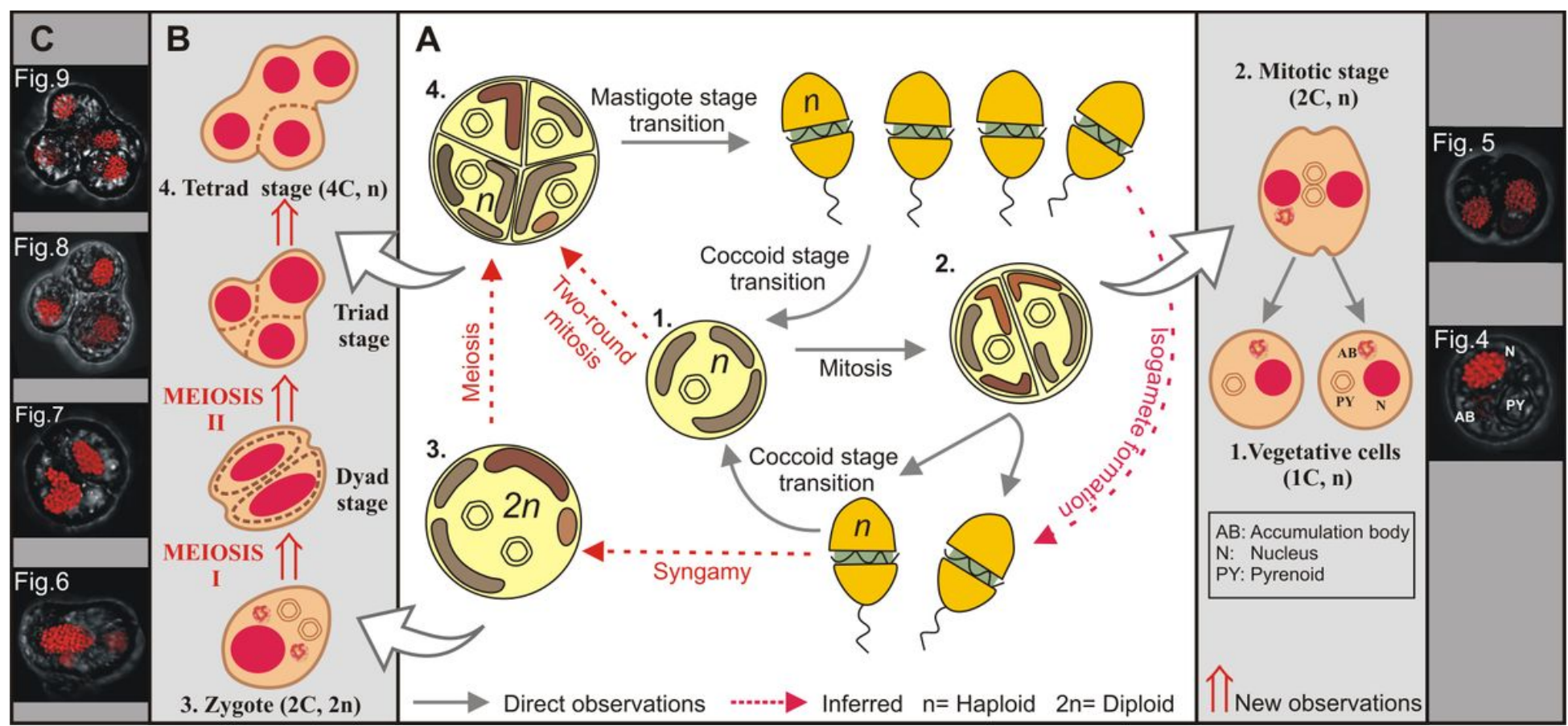

Figure 2

A. Schematic figure of the Symbiodiniaceae life cycle, modified from a depiction by T.C. LaJeunesse (http://tolweb.org/), which was based on (Fitt and Trench 1983). Previously published direct observations include the production of two mobile haploid cells (mastigotes, referred to as 'zoospores' by Freudenthal39) from mitosis within the coccoid stage (termed 'cysts' or 'aplanospores' by Freudenthal39), which could behave as isogametes or transform into coccoid stages. The formation of zygotes through gamete fusion, as well as the formation of tetrads (called 'autospores' by Freudenthal39) via meiosis were hypothesized but not documented. B. Schematic view of the results of the present study in relation to the previously proposed Symbiodiniaceae life cycle (in Fig. 2A). Discriminating morphological features (nuclei, pyrenoids and accumulation bodies) are shown in the sexual stages unless in dyads, triads and tetrads, as these stages are transitory and were found in different evolving grades. C. Confocal images corresponding to the proposed sexual stages depicted in Fig. 2B. 


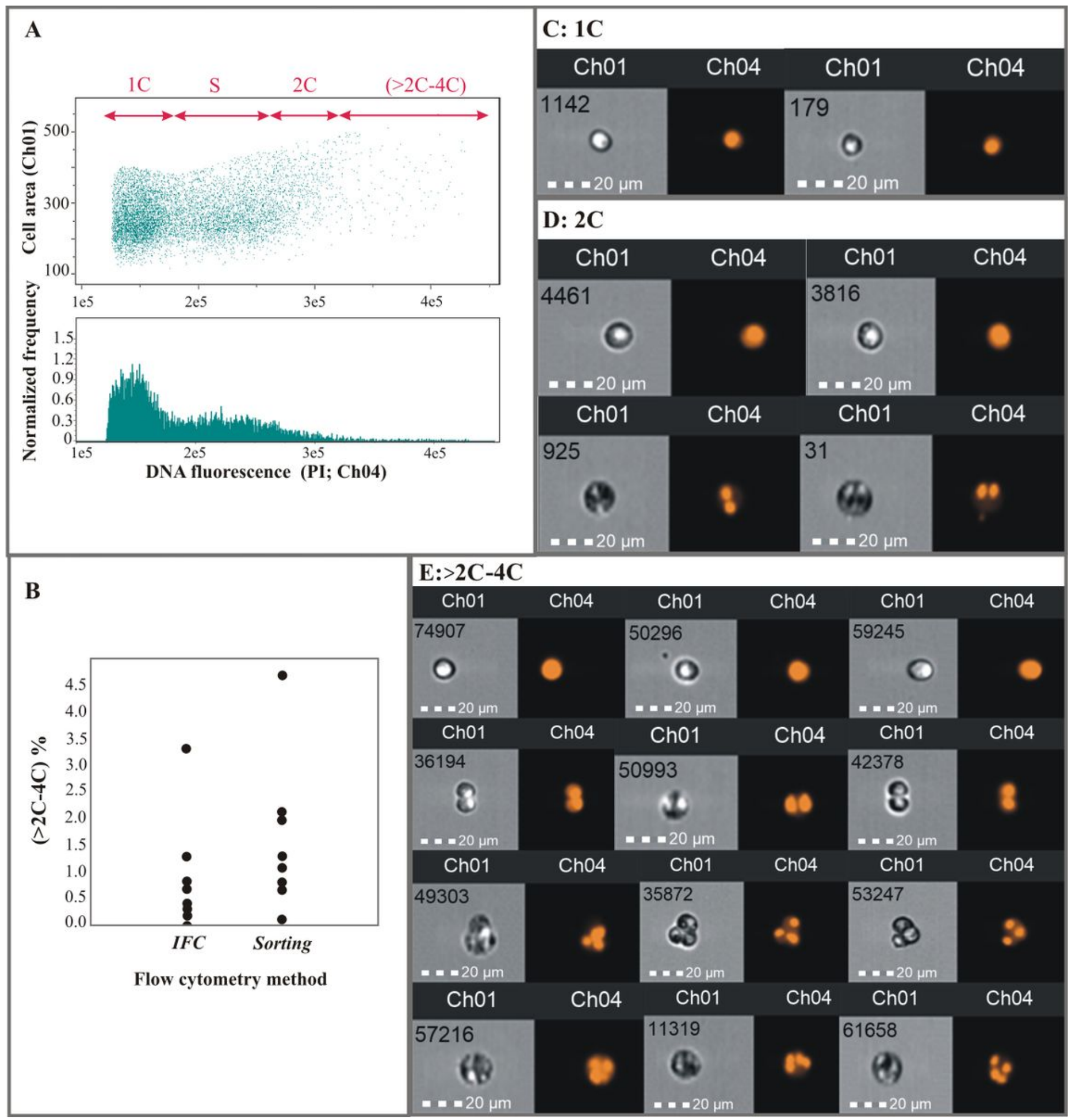

\section{Figure 3}

Imaging Flow Cytometry (IFC) results. A. Summary of the categories and delineation process for classifying Symbiodiniaceae cells according to DNA content (representative data from preliminary sample 10 is displayed) and representative images of each DNA content stage (B-D). B. Percentage (\%) of (>2C-4C) cells in samples analyzed with IFC versus conventional cytometry (Sorting). C. Cells within the $1 \mathrm{C}$ DNA content gate that have a single nucleus. D. Cells within the $2 \mathrm{C}$ DNA content gate that have either 
one nucleus (first row) or two nuclei (second row). E. Cells in the (2C-4C] DNA content group, grouped in rows according to the number of nuclei: 1 (first row), 2 (second row), 3 (third row) and 4 (fourth row).

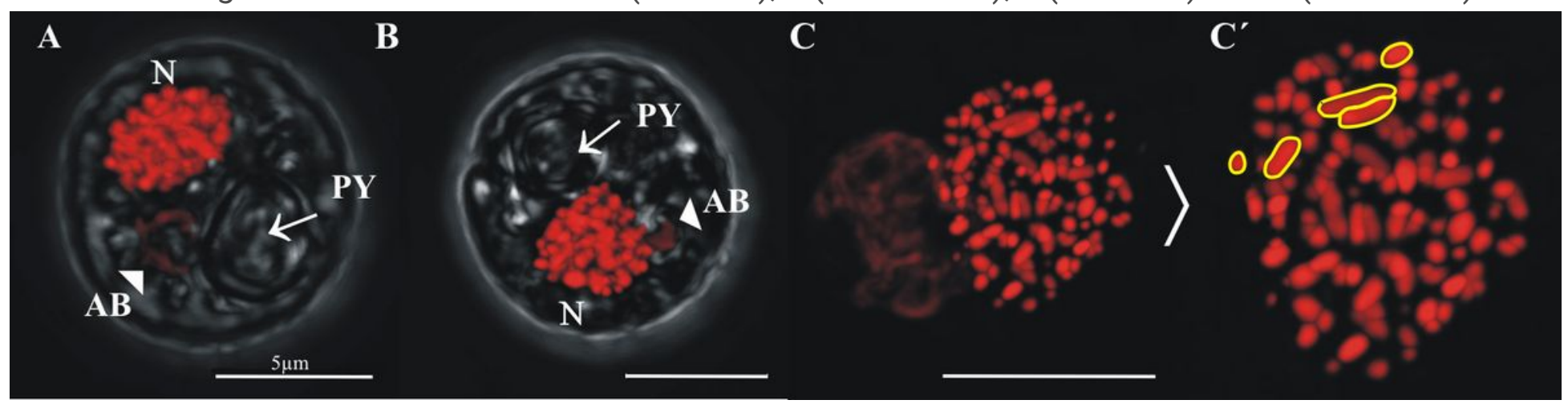

\section{Figure 4}

Confocal images of cells sorted in the 1C DNA content gate. A-B: representative images of cells showing the pyrenoid (PY, arrow), accumulation body (AB, arrowhead) and nucleus (N). C-C': Images of a nucleus showing individualized chromosomes with varied shapes and sizes ( $C^{\prime}$ : examples of individual chromosomes are outlined in yellow). 


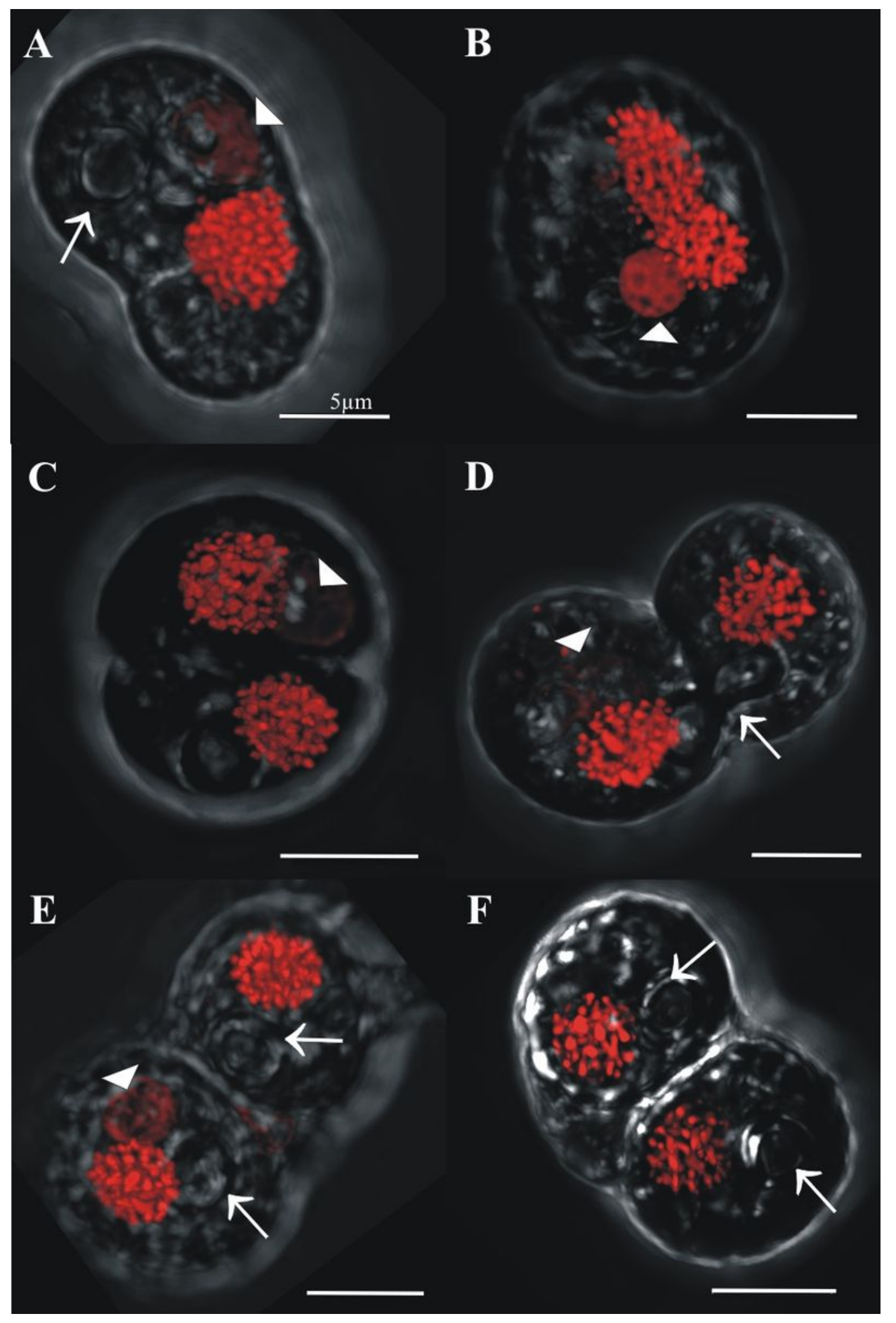

\section{Figure 5}

Confocal images of cells sorted in the 2C DNA content gate and classified as part of the mitotic cycle. Arrows denote the pyrenoids and arrowheads denote the accumulation bodies. In these mitotic cells, only one accumulation body/pyrenoid is detected both in single nucleus cells (A-B) and in pairs which have already duplicated nuclei (C). The pyrenoid is shared in advanced mitotic stages (B) and is duplicated only during more advanced mitotic phases (D-F). 
$\mathbf{A}$

B
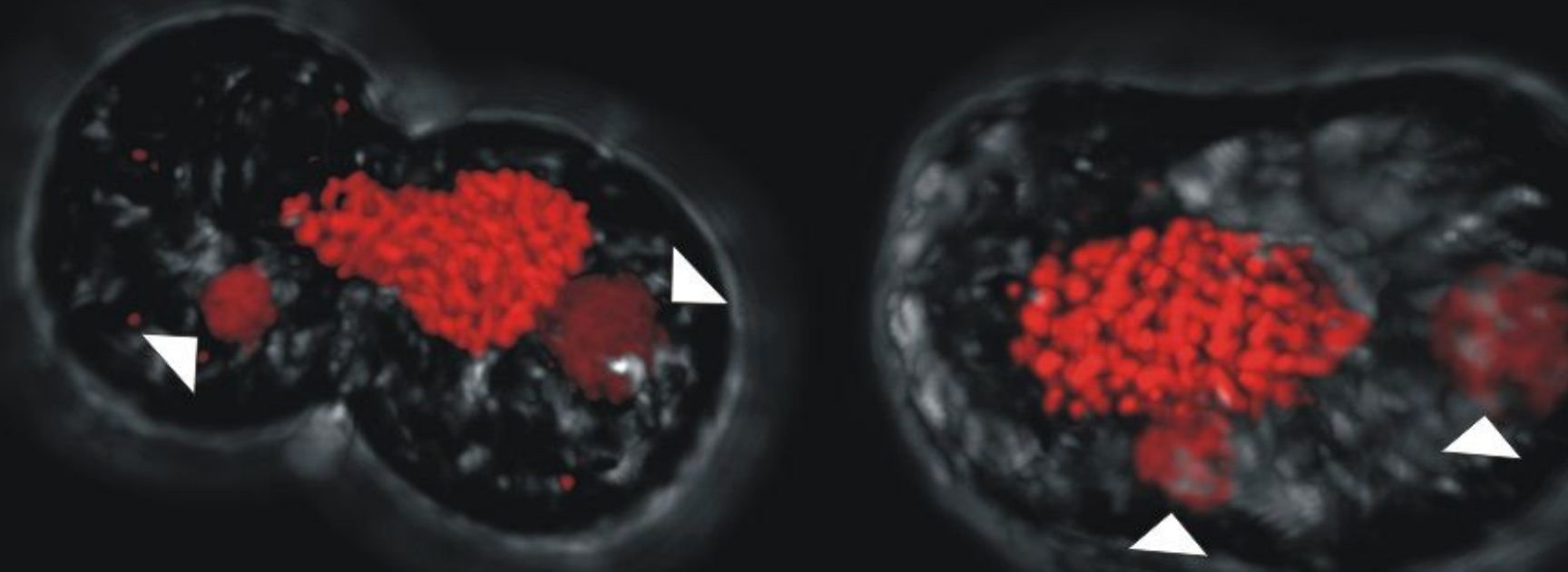

$\mathrm{C}$
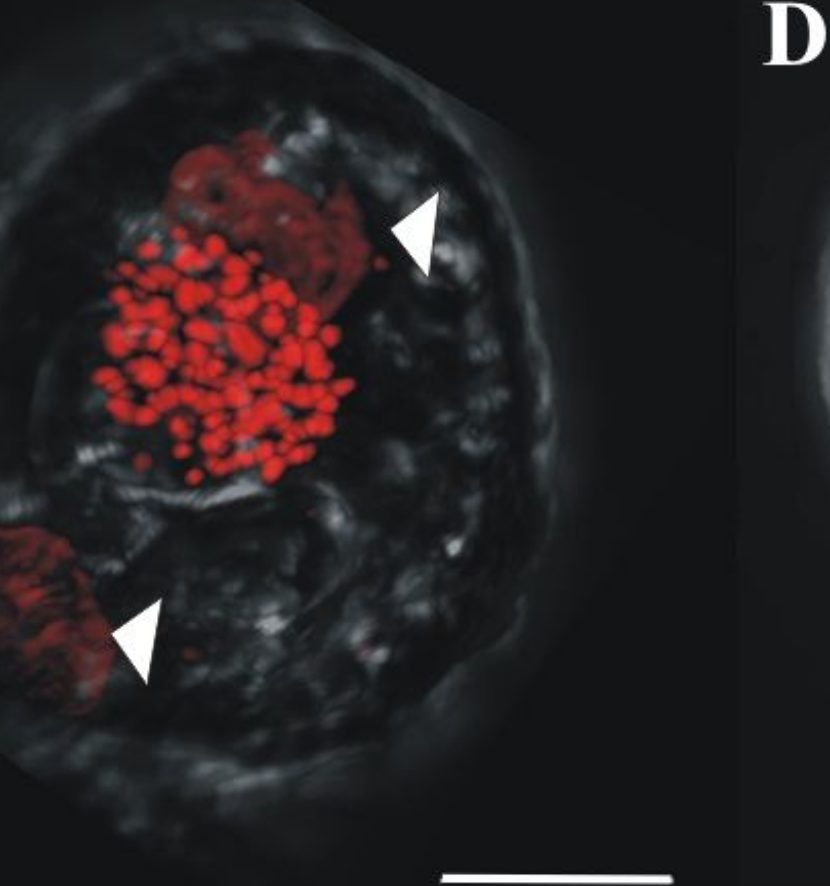

D

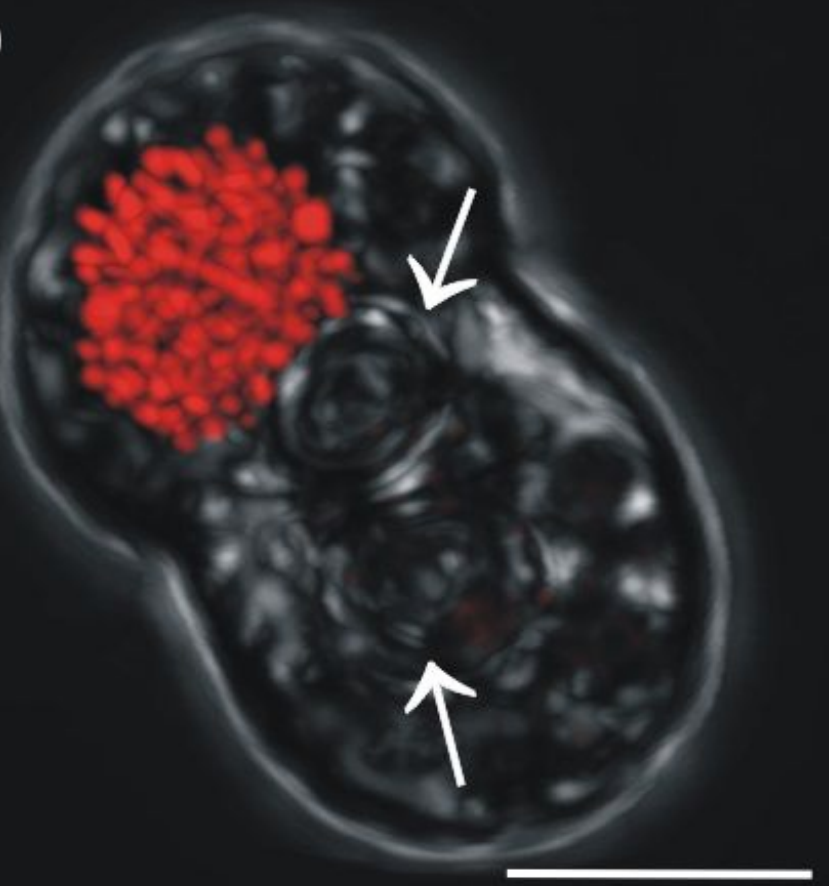

\section{Figure 6}

Confocal images of sorted cells in the 2C DNA content gate and one single nucleus, interpreted as undergoing the meiotic cycle. These cells have duplicated pyrenoids (arrows) and accumulation bodies (arrowheads). 


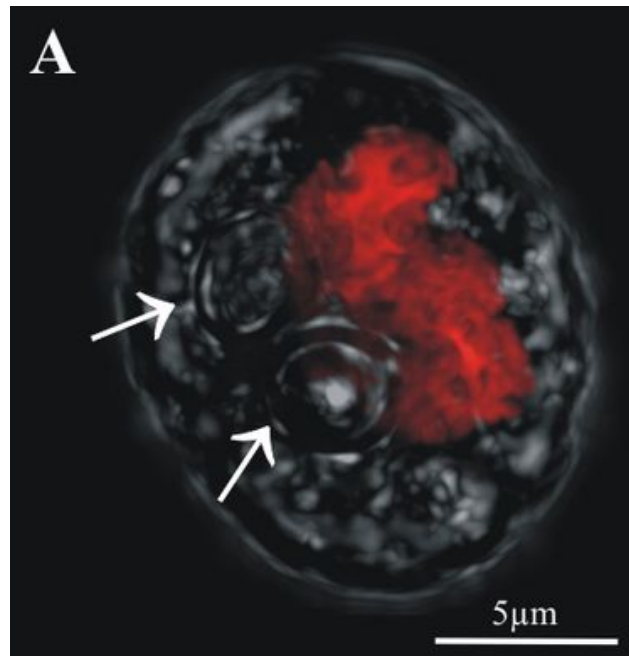

B

C

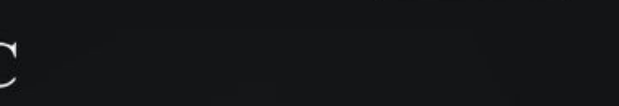

D
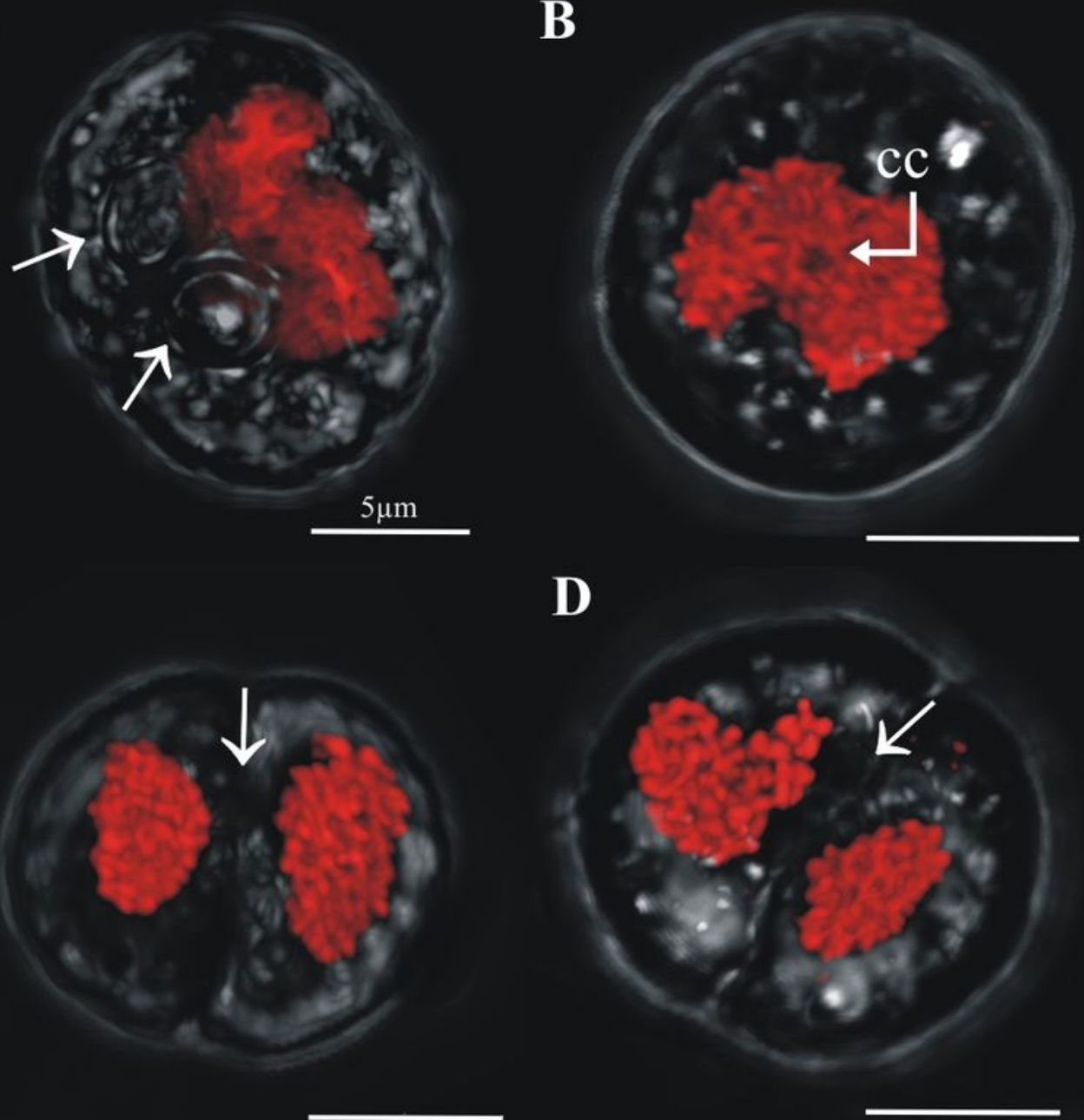

$\mathbf{E}$

$\mathbf{F}$

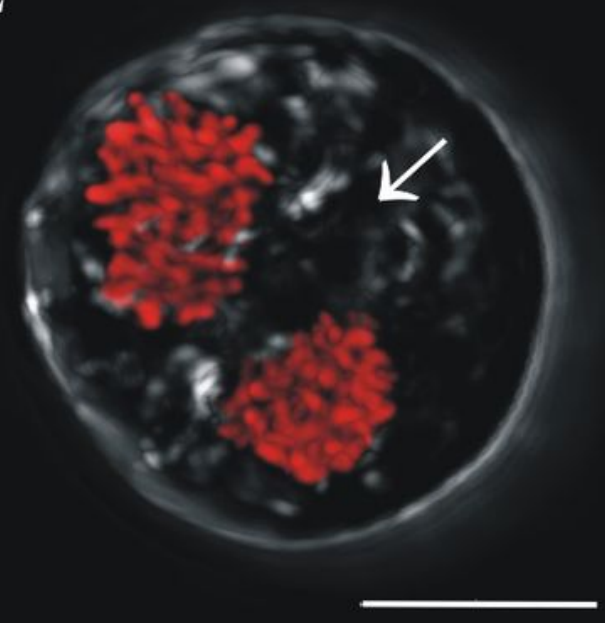

\section{Figure 7}

Confocal images of cells sorted in the (>2C-4C) DNA content gate that have one nucleus or two nuclei. Chromatin was less condensed in these cells, in which two pyrenoids were detected (A, arrows). A central cytoplasmic channel (cc, bent arrow) was observed in one of these cells (B). Cells with two nuclei (dyads) were considered meiotic and are distinct from two nuclei mitotic cells due to their higher DNA content and 
the different morphology and shape displayed between both nuclei (C-F). Dividing furrows in dyads are indicated by an arrow.
Nuclear staining
Transmitted light
Overlay image

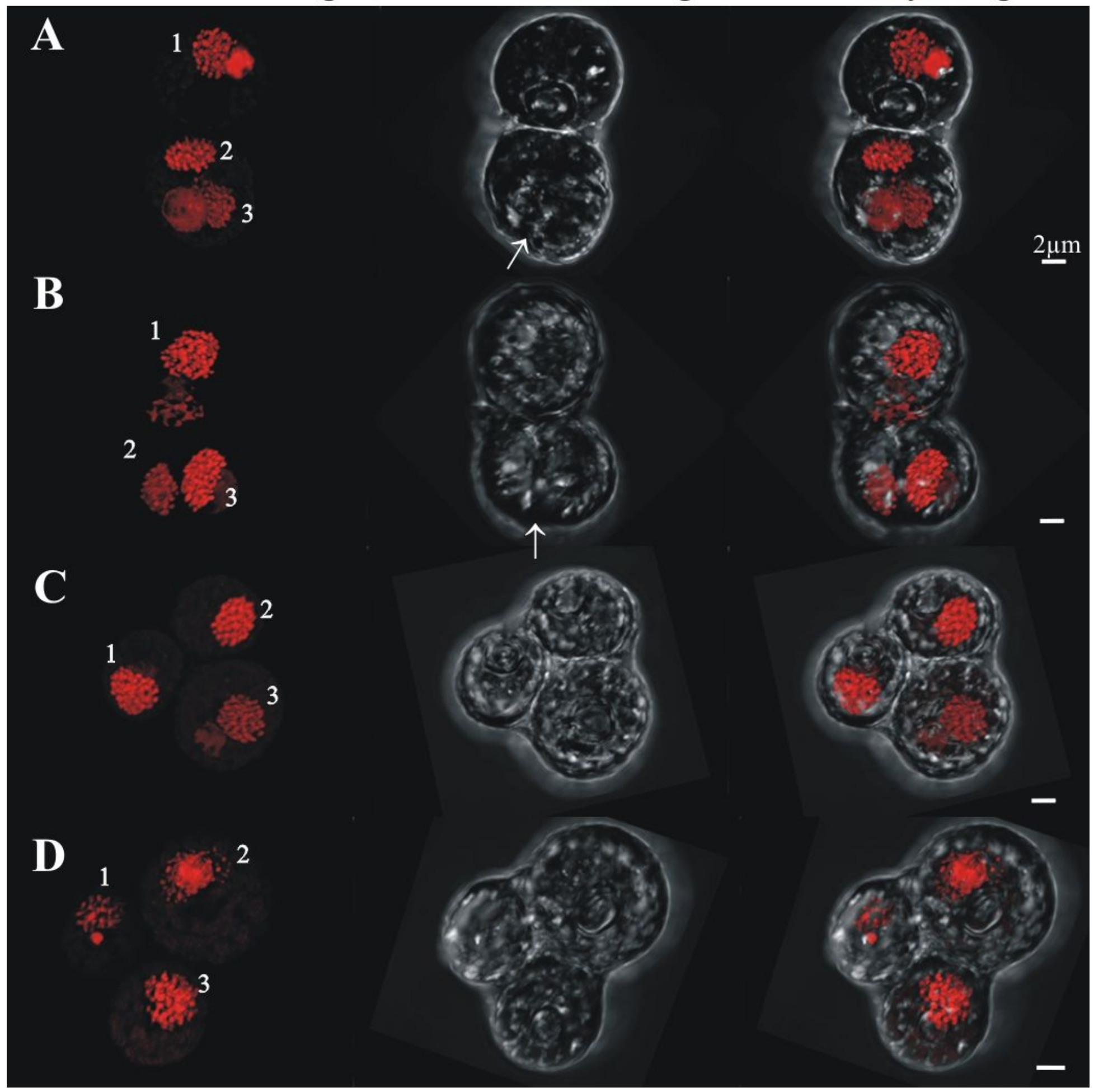

\section{Figure 8}

Confocal images of cells sorted in the (>2C-4C) DNA content gate that have three nuclei and different numbers of lobes in their external morphology (lobes clearly visible in the transmitted light column). A-B: cells with two lobes, one showing a dividing furrow (arrow); C-D: three lobes. 
Nuclear staining

Transmitted light

Overlay image

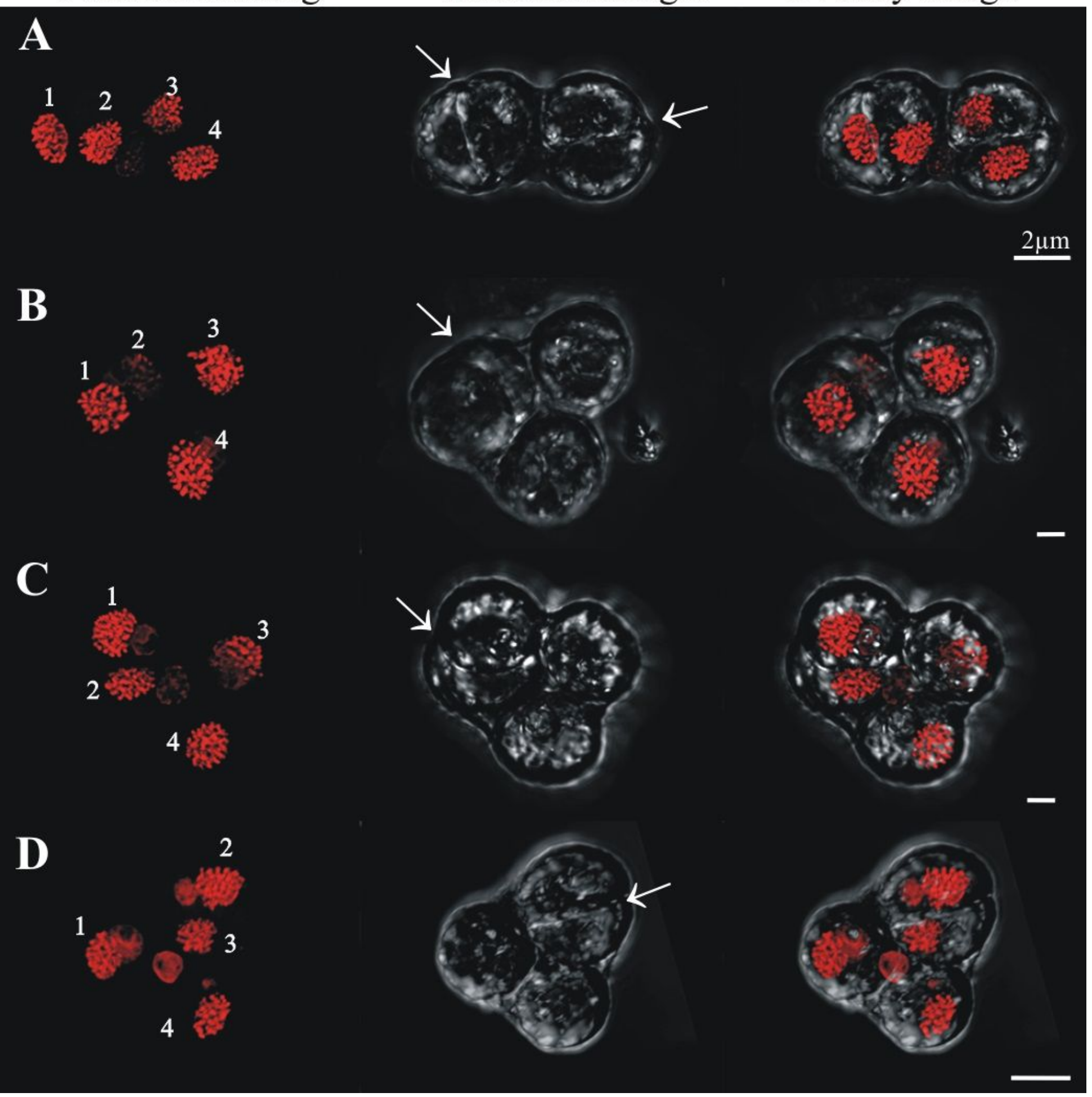

\section{Figure 9}

Confocal images of cells sorted in the (>2C-4C) DNA content gate that have four nuclei and different numbers of lobes in their external morphology (lobes clearly visible in the transmitted light). A: two lobes with a middle furrow of division each (arrows), B-D: three lobes with a middle furrow of division in the biggest lobe (arrow). 


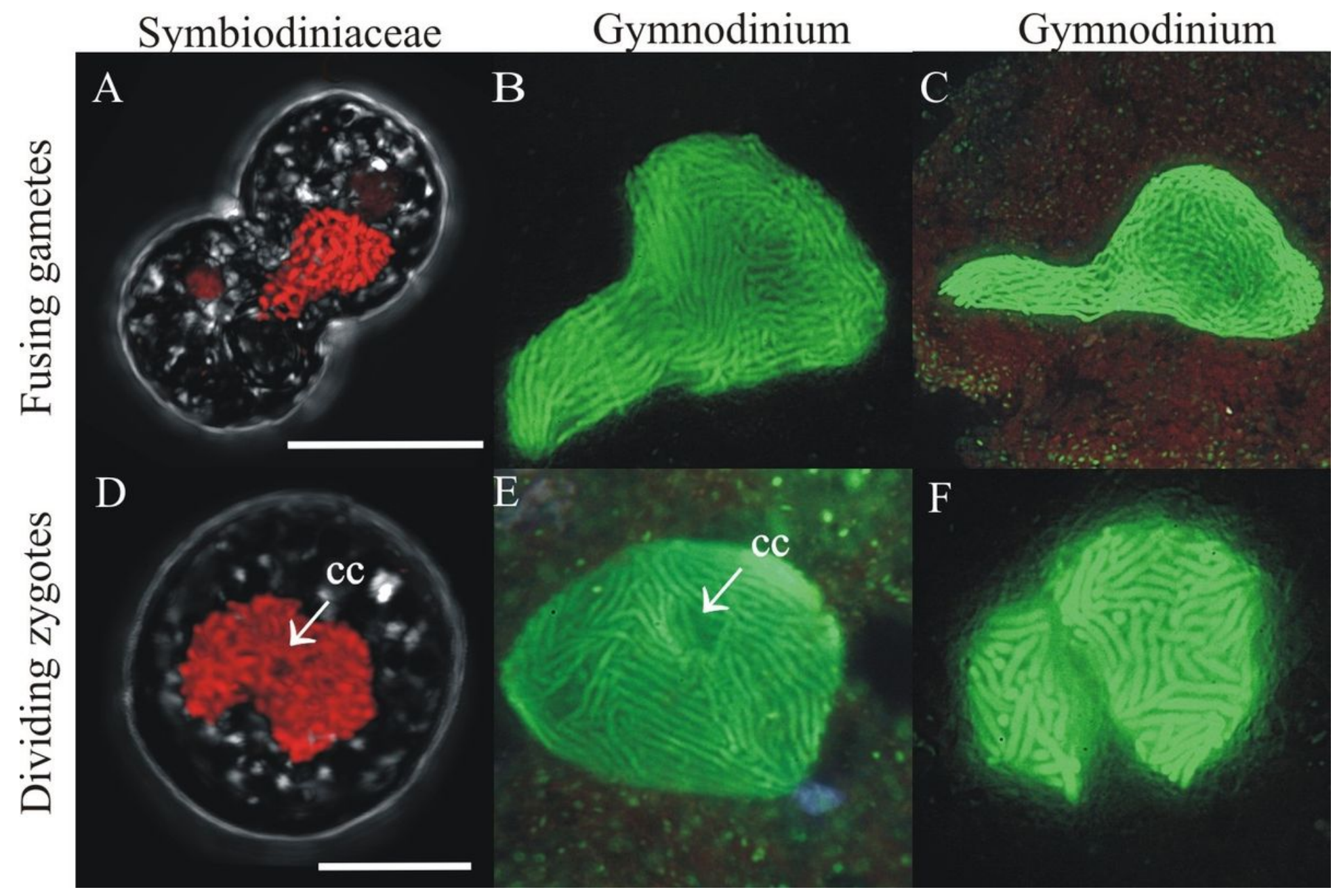

Figure 10

Comparative images show similarities between sexual stages of Gymnodiniaceae and Symbiodiniaceae. A-C Fusing gametes. A: Putative gamete fusion in Symbiodiniaceae. B-C: Nuclear fusion during syngamy in Gymnodinium catenatum. D-F) Zygotes. D: Putative zygote nucleus in Symbiodiniaceae. E-F: Zygote nuclei in G. catenatum and Gymnodinium nolleri in early meiosis I. A central cytoplasmic channel (arrow, cc) is observed in some zygotes, becoming the bilobed nucleus during Meiosis I. Gymnodiniaceae pictures are original, corresponding to the same time lapse series published in45,46. 


\section{Outstanding questions:}

- What are the abiotic triggers of sex in Symbiodiniaceae? For example, do temperature and light influence rates of Symbiodiniaceae meiosis?

- How can we best accelerate the rate of sexual recombination within Symbiodiniaceae to support assisted evolution work to increase the thermotolerance of coral colonies?

- Does meiosis follow a similar process and occur at similar rates across Symbiodiniaceae genera? In conspecific Symbiodiniaceae in different coral hosts?

- When and in what contexts does sex occur in free-living Symbiodiniaceae populations? Is sex more or less frequent than in hospite symbionts?

- How often do hybridization events between distinct Symbiodiniaceae taxa occur in hospite and outside of invertebrate hosts?

- How do Symbiodiniaceae-host interactions facilitate or limit sexual reproduction?

- Is there a relationship between the timing of sexual reproduction in Symbiodiniaceae and their hosts, particularly in coral species that vertically transmit their symbionts to offspring?

\section{Figure 11}

Outstanding question box. Summary of important questions for future research.

\section{Supplementary Files}

This is a list of supplementary files associated with this preprint. Click to download.

- Fig.S24A.m4v

- Fig.S24B.m4v

- Fig.S35A.m4v

- Fig.S35B.m4v

- Fig.S35C.m4v

- Fig.S35D.m4v

- Fig.S35E.m4v

- Fig.S35F.m4v

- Fig.S46A.m4v 
- Fig.S46B.m4v

- Fig.S46C.m4v

- Fig.S46D.m4v

- Fig.S57A.m4v

- Fig.S57B.m4v

- FIGURELEGENDSOFSUPPLEMENTARYFILESS2S7.pdf

- Fig.S57C.m4v

- Fig.S24A.m4v

- Fig.S57D.m4v

- Fig.S24B.m4v

- Fig.S57E.m4v

- Fig.S35A.m4v

- Fig.S35B.m4v

- Fig.S68A.m4v

- Fig.S68B.m4v

- Fig.S35C.m4v

- Fig.S35D.m4v

- Fig.S68C.m4v

- Fig.S68D.m4v

- Fig.S35E.m4v

- Fig.S79A.m4v

- Fig.S35F.m4v

- Fig.S46A.m4v

- Fig.S79B.m4v

- Fig.S46B.m4v

- Fig.S79C.m4v

- Fig.S79D.m4v

- Fig.S46C.m4v

- FIGURELEGENDSOFSUPPLEMENTARYFILESS2S7.pdf

- Fig.S46D.m4v

- SUPPLEMENTARYFIGURES1.pdf

- Fig.S57D.m4v

- Fig.S57F.m4v

- Fig.S57A.m4v 
- Fig.S57B.m4v

- Fig.S57C.m4v

- Fig.S57E.m4v

- Fig.S57F.m4v

- Fig.S68A.m4v

- Fig.S68B.m4v

- Fig.S68C.m4v

- Fig.S68D.m4v

- Fig.S79A.m4v

- Fig.S79B.m4v

- Fig.S79C.m4v

- Fig.S79D.m4v

- SUPPLEMENTARYFIGURES1.pdf 